\title{
PETROGRAFIA, QUÍMICA MINERAL E GEOTERMOBAROMETRIA DE RETROECLOGITO NO GRUPO ARAXÁ NA REGIÃO DA ZONA DE CISALHAMENTO VARGINHA, SUDOESTE DE MINAS GERAIS
}

\author{
PETROGRAPHY, MINERAL CHEMISTRY AND GEOTHERMOBAROMETRY OF \\ RETROECLOGITE OF ARAXÁ GROUP FROM VARGINHA SHEAR ZONE REGION, \\ SOUTHWEST OF MINAS GERAIS STATE
}

\section{Thaís Güitzlaf LEME ${ }^{1}$, Guillermo Rafael Beltran NAVARRO², Antenor ZANARDO², Cibele Carolina MONTIBELLER ${ }^{1}$}

\author{
${ }^{1}$ Pós-Graduação em Geociências e Meio Ambiente, Instituto de Geociências e Ciências Exatas, Universidade Estadual Paulista, \\ Campus de Rio Claro. Email: thais.guitzlaf@hotmail.com, cibele.cm@outlook.com. \\ ${ }^{2}$ Instituto de Geociências e Ciências Exatas, Universidade Estadual Paulista. Emails: guillermo.navarro@unesp.br, \\ antenor.zanardo@unesp.br

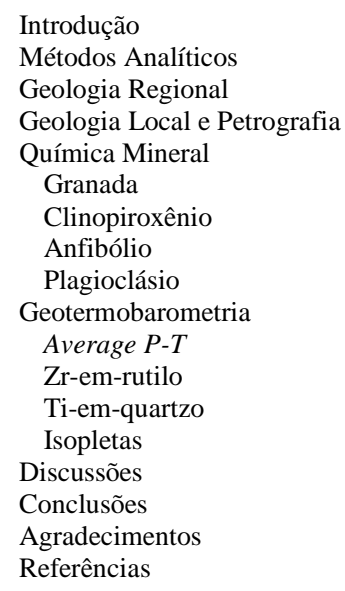

RESUMO - A área de estudo está situada no sudoeste do estado de Minas Gerais, a norte da cidade de Guaxupé e nas proximidades do distrito de Santa Cruz do Prata (município de Guaranésia), região afetada pela Zona de Cisalhamento Varginha. É constituída por litotipos atribuídos ao Grupo Araxá, posicionados em zona de sutura de blocos crustais, amalgamados durante a orogênese brasiliana no Neoproterozoico (Zona de Sutura de Alterosa). Nessa região, o Grupo Araxá é composto por metassedimentos pelíticos a psamo-pelíticos com intercalações de ortognaisses e de rochas metamáficas e metaultramáficas. Intercaladas nestes litotipos, foram descritas ocorrências de rochas metamáficas de alta pressão, com texturas simplectíticas e coroníticas, interpretadas como retroeclogitos. Neste trabalho são apresentados dados petrográficos, de química mineral e geotermobarométricos obtidos em retroeclogito. Os resultados de geotermobarometria por elementos traço (Zr-em-rutilo e Ti-em-quartzo) indicam condições de reequilíbrio metamórfico mais antigas em fácies eclogito, com temperatura de $763^{\circ} \mathrm{C}$ e pressão de $14,4 \mathrm{kbar}$. As condições de reequilíbrio em fácies anfibolito superior, calculadas pelo software THERMOCALC, são de 12,5 $\pm 0,8 \mathrm{kbar}$ e $799 \pm 37^{\circ} \mathrm{C}$. Os dados texturais e mineralógicos, associados aos dados de geotermobarometria, sugerem trajetória P-T-t horária associada a descompressão quase isotérmica. Os resultados são compatíveis com zonas de colisão continental com espessamento crustal.

Palavras-Chave: Fácies eclogito, Zona de Cisalhamento Varginha, Zona de Sutura de Alterosa, Faixa Brasília Meridional. Cruz do Prata district (Guaranésia municipality), a region affected by the Varginha Shear Zone. It is constituted of lithotypes attributed to the Araxá Group, placed in a suture zone of crustal blocks, and amalgamated during the Brazilian orogenesis in Neoproterozoic (Alterosa Suture Zone). In this region, the Araxá Group is composed of pelitic to psamo-pelitic metasediments with orthogneisses, metamafic and metaultramafic rocks intercalations. Interleaved with these lithotypes, it was described high pressure metamafic rocks occurrences with symplectic and coronitic textures which were interpreted as retroeclogites. In this paper are presented petrographic, mineral chemistry and geothermobarometric data obtained in retroeclogite. The geothermobarometry results by trace elements (Zr-in-rutile and Ti-in-quartz) indicate older metamorphic rebalancing conditions in eclogite facies, with temperature of $763^{\circ} \mathrm{C}$ and pressure of $14.4 \mathrm{kbar}$. The rebalancing conditions in upper amphibolite facies, calculated by the THERMOCALC software, are $12.5 \pm 0.8 \mathrm{kbar}$ and $799 \pm 37^{\circ} \mathrm{C}$. The textural and mineralogical data, combined with geothermobarometric data, suggest a clockwise P-T-t path associated to near isothermal decompression. The results are compatible with continental collision zones with crustal thickening.

Keywords: Eclogite Facies, Varginha Shear Zone, Alterosa Suture Zone, Southern Brasília Belt.

\section{INTRODUÇÃO}

A porção sul/sudoeste do estado de Minas neoproterozoica (complexos Barbacena e Gerais compreende terrenos pré-cambrianos, Guaxupé), circundadas por sequências constituídos por rochas de idade arqueana a metassedimentares alóctones, como os grupos 
Araxá, Andrelândia e São João Del Rei, autóctones e/ou para-autóctones, como os grupos Canastra e Bambuí, e zonas de cisalhamento neoproterozoicas, que evidenciam uma história tectono-metamórfica complexa.

A estruturação regional, reconhecida pela gravimetria, mostra blocos crustais justapostos, reconhecidos a norte, o Cráton do São Francisco e, a sul, o Bloco ou Placa Paranapanema. Os limites dos blocos são definidos por grandes descontinuidades gravimétricas (anomalias tipo Boulger) e correspondem a uma faixa de deformação intensa, marcada pela atuação do Cinturão de Cisalhamento Campo do Meio, e definindo a Zona de Sutura de Alterosa (Almeida et al., 1980; Hasui, 1982; Haralyi \& Hasui, 1982a, b; Haralyi et al., 1985; Hasui et al., 1990; Zanardo et al., 2006).

Esta faixa aflora a sul do Complexo Barbacena, na região de Jacuí - Bom Jesus da Penha - Petúnia, e a norte do Complexo Guaxupé, na região de Guaranésia - Guaxupé Monte Belo, e suas litologias são atribuídas ao Grupo Araxá (Zanardo, 1992, 2003; Zanardo et al., 1996, 2006) (Figura 1).

As zonas de sutura são cinturões intensamente deformados que representam antigos orógenos colisionais e bacias oceânicas, e são reconhecidas pela ocorrência de complexos de subducção, complexos acrescionários, arcos magmáticos continentais e oceânicos, cinturões de empurrão e terrenos de alta a ultra alta pressão e são definidas, principalmente, por meio de estudos geofísicos (Chetty et al., 2011).

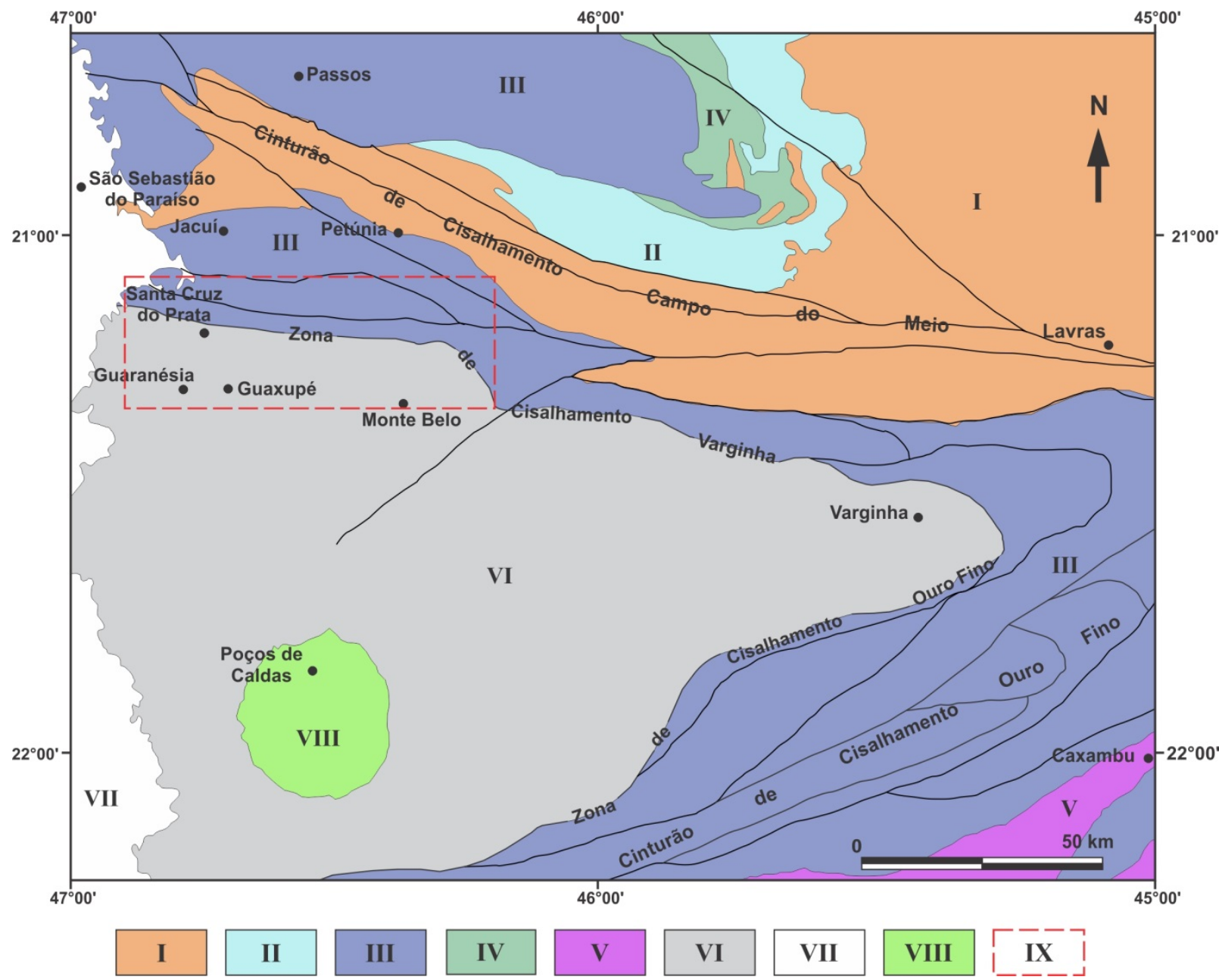

Figura 1 - Mapa geológico da região sudoeste do estado de Minas Gerais (Modificado de Zanardo, 2003). I - Complexo Barbacena. II - Grupo Bambuí. III - Grupos Araxá, Andrelândia e São João Del Rei; Complexos Itapira e Amparo. IV Grupo Canastra. V - Complexo Socorro. VI - Complexo Guaxupé. VII - Bacia do Paraná. VIII - Maciço Alcalino de Poços de Caldas. IX - Localização da figura 2.

A ocorrência de rochas metamáficas (eclogitos e/ou retroeclogitos) nas zonas de sutura são fundamentais para a investigação e compreensão das condições metamórficas às quais as rochas foram submetidas.
Intercalado nas litologias metassedimentares atribuídas ao Grupo Araxá nesta região (logo a norte da Zona de Cisalhamento Varginha), foram descritas ocorrências de rochas metamáficas com texturas simplectíticas e com 
dados de química mineral característicos de rochas de zonas de alta pressão (Zanardo, 1992; Del Lama et al., 1994).

As ocorrências de rochas de alta pressão associadas ao Grupo Araxá são poucas, e foram descritas na região de São Sebastião do Paraíso (Hoppe et al., 1985, 1989; Luvizotto, 2003) e na região do distrito de Santa Cruz do Prata, município de Guaranésia (Zanardo, 1992; Del Lama et al., 1994), e são representadas por granada anfibolitos com plagioclásio e clinopiroxênio, com texturas simplectíticas e coroníticas, sendo denomi- nadas de "retroeclogitos".

Apesar de sua importância, as ocorrências de rochas de alta pressão registradas no Grupo Araxá ainda carecem de estudos mais aprofundados que envolvam detalhamento petrográfico, estudos de química mineral e de geotermobarometria.

Assim, o presente trabalho apresenta a caracterização petrográfica, de química mineral e geotermobarométrica de uma destas ocorrências denominadas de retroeclogitos, no Grupo Araxá, logo a norte da Zona de Cisalhamento Varginha.

\section{MÉTODOS ANALÍTICOS}

Amostras de retroeclogito foram selecionadas para estudos petrográficos detalhados, análises de química mineral e cálculos geotermobarométricos.

As análises de química mineral foram realizadas no Laboratório de Microssonda Eletrônica do Departamento de Petrologia e Metalogenia do Instituto de Geociências e Ciências Exatas, Unesp, Campus de Rio Claro, por microssonda eletrônica da marca JEOL modelo JXA-8230 superprobe. As condições analíticas foram de aceleração de $15 \mathrm{kV}$, corrente de $20 \mathrm{nA}$ e diâmetro do feixe de $10 \mu \mathrm{m}$, para análise de cristais de anfibólio, clinopiroxênio, granada e plagioclásio, e condições de $20 \mathrm{kV}$ de aceleração, corrente de 80 nA e diâmetro do feixe de $5 \mu \mathrm{m}$ para análise de elementos traço em cristais de rutilo e quartzo.

Os resultados representativos das análises dos elementos maiores são apresentados nas tabelas 1, 2, 3 e 4.

Os cálculos geotermobarométricos foram realizados utilizando o software THERMOCALC 3.26, modo Average-PT (Powell \& Holland, 1994), e os geotermômetros Zr-em-rutilo, calibração de Tomkins et al. (2007) e Ti-emquartzo, calibração de Thomas et al. (2010). As abreviaturas minerais utilizadas neste trabalho são as propostas por Kretz (1983).

\section{GEOLOGIA REGIONAL}

$\mathrm{Na}$ região da área de estudo, ocorrem unidades litoestratigráficas que compõem dois blocos continentais associados a colisão neoproterozoica, separados pela Zona de Sutura de Alterosa, que representa o limite entre os dois domínios litológicos (Almeida et al., 1980; Haralyi \& Hasui, 1982a, b; Haralyi et al., 1985; Zanardo et al., 2006).

O Complexo Barbacena, localizado a norte, é constituído por uma complexa associação litológica que inclui terrenos migmatíticos e granito-gnaisse-greenstone, além de intercalações tectônicas de rochas supracrustais alóctones e autóctones dos grupos Araxá, Canastra e Bambuí (Figura 1).

O Complexo Guaxupé (Oliveira et al., 1986; Del Lama, 1998; Del Lama et al. 2000; Zanardo, 2003; Zanardo et al. 2006), domínio norte da Nappe Socorro-Guaxupé (Campos Neto et al., 1984; Campos Neto \& Caby, 1999), ocorre a sul (Figura 1), e é composto por litologias ortoderivadas de natureza intermediária a ácida (granulitos félsicos a máficos), com intercalações de metassedimentos (pelíticos, psamíticos e carbonáticos), de rochas metamáficas (granulitos básicos) e, mais raramente, de rochas metaultramáficas (Del Lama et al., 2000; Zanardo et al., 2006).

Encaixado entre essas unidades, a norte do Complexo Guaxupé e a sul da exposição do Complexo Barbacena, ocorre uma faixa estruturada segundo a direção E-W a WNWESE (Figura 1), atribuída por Cavalcante et al. (1979) ao Complexo Campos Gerais, por Trouw et al. (1984) ao Grupo Andrelândia e São João Del Rei e por Zanardo (1992, 2003) e Zanardo et al. (1996, 2006) ao Grupo Araxá.

O Grupo Araxá, nessa porção, é constituído por metassedimentos pelíticos a psamopelíticos, com intercalações de ortognaisses e granitoides sin- a tardi tectônicos e intercalações tectônicas de rochas metamáficas e metaultramáficas, afetadas pelo Cinturão de Cisalhamento Campo do Meio. Os litotipos são 
representados por gnaisses paraderivados e ortoderivados com composição granítica a tonalítica, xistos e quartzitos com ou sem granada e/ou cianita, anfibolitos, anfibólio gnaisses, rochas metaultramáficas e subordinadamente rochas calciossilicáticas e gonditos (Zanardo, 1992, 2003; Del Lama, 1993, 1998; Del Lama et al., 1994; Zanardo et al., 1996, 2006).

\section{GEOLOGIA LOCAL E PETROGRAFIA}

Na região entre as Zonas de Cisalhamento Varginha e Campos Gerais (Figura 2), o Grupo Araxá é constituído por cianita-granada gnaisses, cianita-granada gnaisses quartzosos, cianita-granada xistos, cianita-granada quartzitos, granada quartzitos e granada gnaisses (com anfibólio, biotita e clinopiroxênio), além de intercalações subordinadas de rochas metamáficas como anfibolitos com granada e clinopiroxênio, e rochas metaultramáficas. A estrutura dessas rochas é marcada por forte anisotropia, com foliação orientada segundo a direção E-W a WNW, milonítica a comumente blastomilonítica (Leme, 2019).
Nessa porção, logo a noroeste do distrito de Santa Cruz do Prata (extremo sudeste da folha topográfica de Monte Santo de Minas) (Figura 2), intercalada em rochas metassedimentares, foi descrita uma ocorrência de rocha metamáfica com granada, clinopiroxênio, plagioclásio e anfibólio, interpretada como retroeclogito (Leme, 2019), anteriormente descrita como granulito tonalito máfico por Nascimento (2010).

O retroeclogito constitui uma lente métrica intercalada tectonicamente em metassedimentos pelíticos com granada e cianita, concordante com a direção das rochas encaixantes, e apresenta contato brusco com estas.

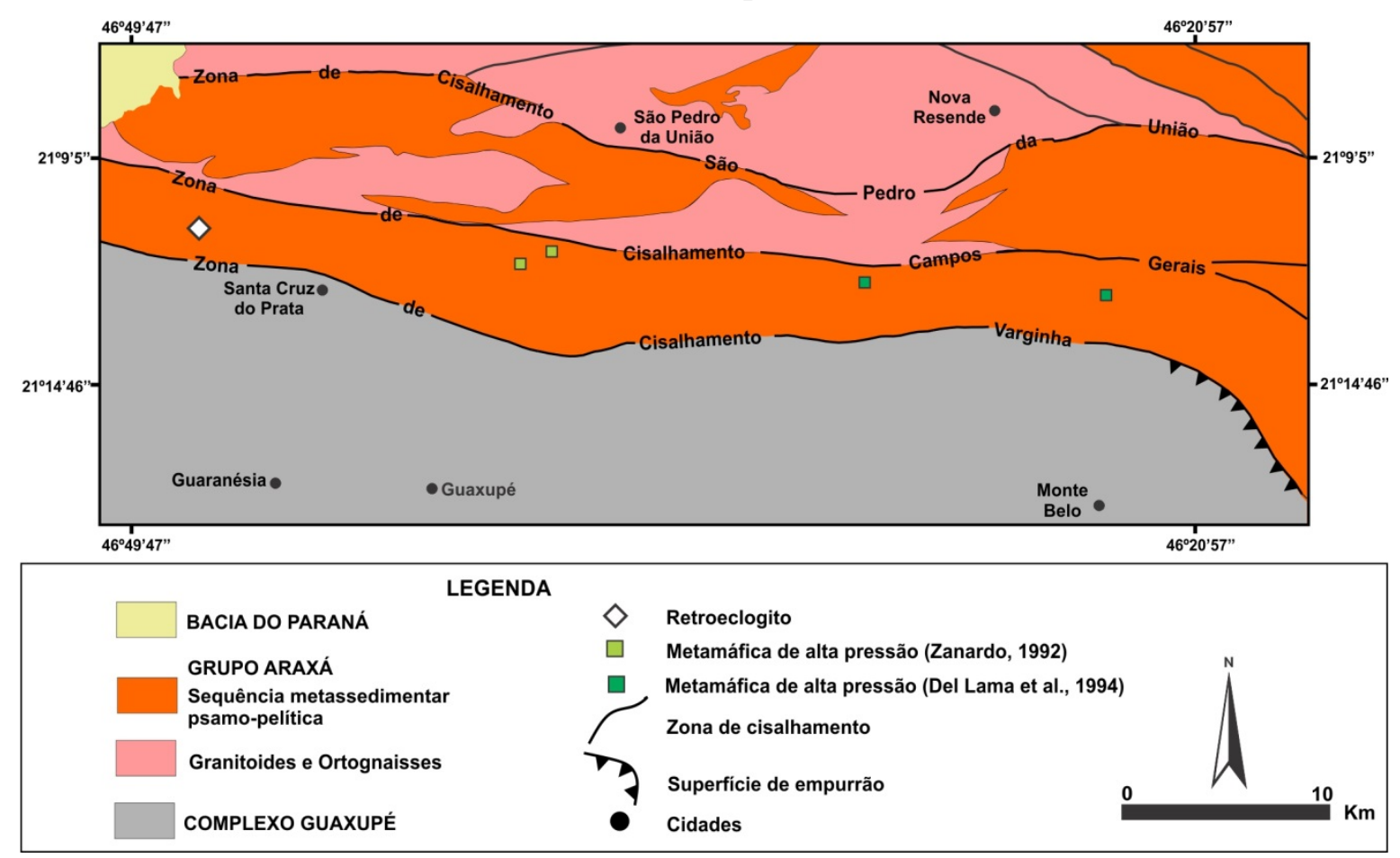

Figura 2 - Mapa geológico simplificado mostrando a localização da ocorrência de retroeclogito deste trabalho (Modificado de Zanardo et al., 2006; Leme, 2019). O mapa mostra a ocorrência de rochas metamáficas de alta pressão estudadas por Zanardo (1992) e Del Lama et al. (1994).

É uma rocha de coloração verde escuro com cristais de granada milimétricos de coloração marrom avermelhada (Figura 3A), apresenta estrutura anisotrópica, com textura granoblástica inequigranular e domínios porfiroblásticos (Figura 3B, C). É constituída por granada (3035\%), clinopiroxênio (30-35\%), anfibólio $( \pm 10 \%)$, plagioclásio $( \pm 10 \%)$, quartzo $(5-10 \%)$, com mineralogia acessória composta por ilmenita (2-3\%), rutilo ( $<1-2 \%)$, titanita $(<1 \%)$, apatita $(<1 \%)$, além de traços de zircão.

A granada ocorre como cristais subédricos, anédricos a arredondados, com bordas irregulares e lobuladas e dimensões que variam de $500 \mu \mathrm{m}$ a $5.000 \mu \mathrm{m}$. Os cristais são poiquilíticos, com inclusões de quartzo, plagioclásio, clinopiroxênio, rutilo, anfibólio, ilmenita e zircão. Frequentemente ocorrem 
circundados por coroas de plagioclásio e quartzo (Figura 3D, E). A granada em contato com o clinopiroxênio é menos frequente.

Os cristais de clinopiroxênio são anédricos a subédricos, com dimensões médias da ordem de $500 \mu \mathrm{m}$ e podem alcançar dimensões de até
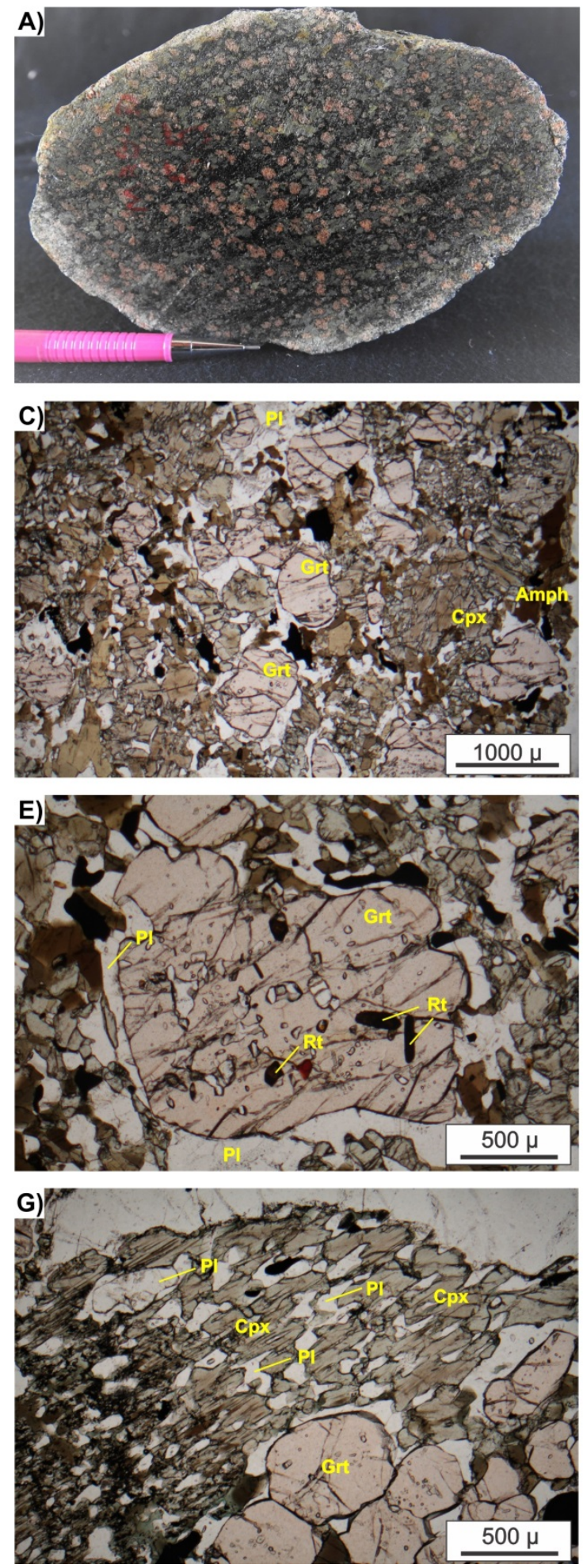

Figura 3 - A): Amostra de retroeclogito; B-C): Textura granoblástica constituída dominantemente por cristais de clinopiroxênio com domínios porfiroblásticos compostos por granada (Polarizadores paralelos); D-E): Cristais de granada poiquilíticos com coronas de plagioclásio (Polarizadores paralelos); F-G): Cristais de clinopiroxênio com intercrescimento lamelar e venular de plagioclásio (Polarizadores paralelos); H): Cristal de clinopiroxênio com intercrescimento de ilmenita e plagioclásio (Polarizadores paralelos). Amph: anfibólio, Cpx: clinopiroxênio, Grt: granada, Ilm: ilmenita, Pl: plagioclásio, Rt: rutilo. 
O clinoanfibólio ocorre sob a forma de cristais anédricos a subédricos, com dimensões que podem alcançar até $3.000 \mu \mathrm{m}$. Os cristais apresentam forte pleocroísmo em tons de marrom esverdeado a marrom pálido, e mostram-se associados principalmente aos cristais de clinopiroxênio, corroendo estes e também intercrescidos nos cristais simplectíticos. Localmente formam coroas em torno de cristais de clinopiroxênio e ilmenita.

Os cristais de plagioclásio são anédricos a subédricos, com contatos retos a predominantemente lobulados e dimensões da ordem de $200 \mu \mathrm{m}$. Possuem extinção ondulante leve e raramente apresentam geminação polissintética nítida. Constituem coroas em torno de cristais de granada com contatos retos entre si (textura de equilíbrio) e ocorrem com formas lamelares a vermiformes no interior de cristais de clinopiroxênio, desenvolvendo textura simplectítica.

Os cristais de quartzo são anédricos, com dimensões geralmente inferiores a $500 \mu \mathrm{m}$ e
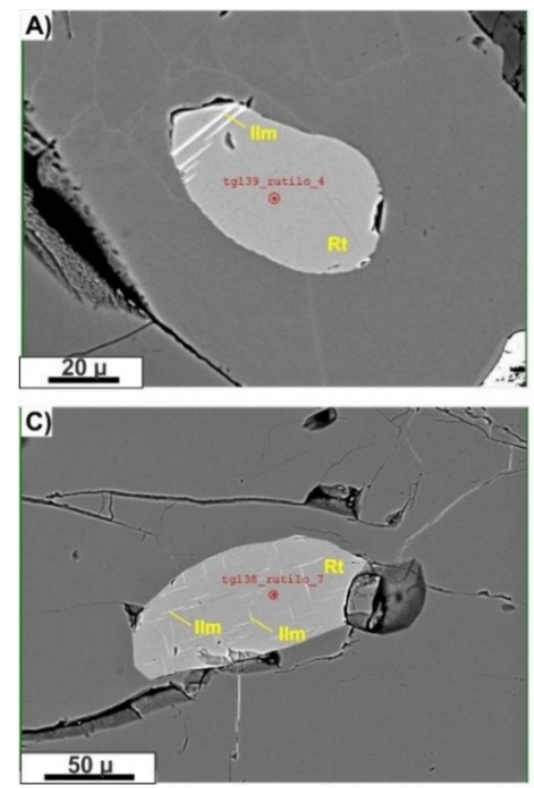

mostram extinção ondulante leve a moderada.

A ilmenita ocorre sob formas subédricas a anédricas, com dimensões que variam de inferiores a $400 \mu \mathrm{m}$ a $1.500 \mu \mathrm{m}$, associada aos minerais máficos, principalmente ao anfibólio e também ocorre inclusa em cristais de granada. Localmente apresenta coroas de anfibólio e textura vermiforme com o clinopiroxênio (Figura 3H).

Os cristais de rutilo são subédricos ou anédricos e arredondados, com dimensões inferiores a $300 \mu \mathrm{m}$ e ocorrem inclusos em cristais de granada (Figura 3E). Frequentemente apresentam lamelas de exsolução de ilmenita (Figura 4A, B, C, D).

A titanita ocorre como cristais arredondados, associada aos minerais máficos, e pode ocorrer substituindo cristais de rutilo e ilmenita ou formando coroas em torno destes. A apatita é arredondada, com dimensões da ordem $100 \mu \mathrm{m}$ e ocorre dispersa pela rocha. O zircão é arredondado, com tamanho inferior a $100 \mu$ m e pode estar disperso ou incluso em cristais de granada.
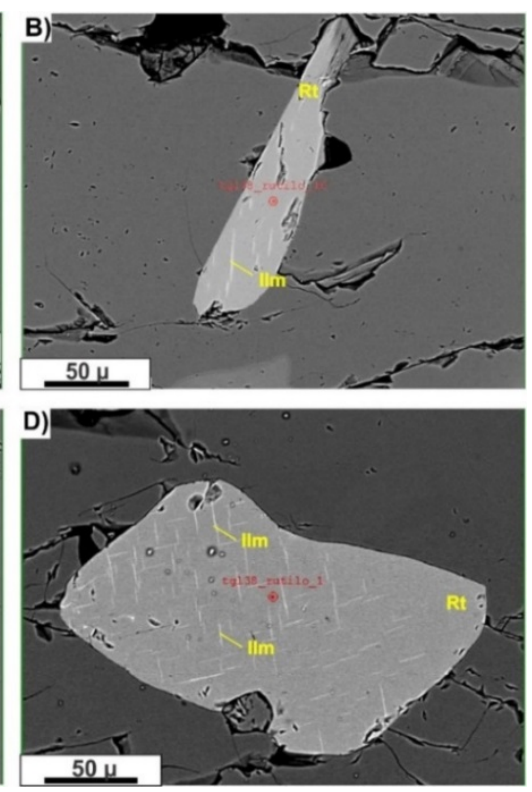

Figura 4 - Imagens retroespalhadas de cristais de rutilo inclusos em granada analisados nas amostras de retroeclogito. A-D): Cristal de rutilo com finas lamelas de exsolução de ilmenita. Ilm: ilmenita, Rt: rutilo.

\section{QUÍMICA MINERAL}

\section{Granada}

A composição dos cristais de granada analisados é dominada pelas moléculas de almandina (Alm49,72-60,03) e grossulária (Grs 16,68-30,40), seguida por proporções intermediárias de piropo $\left(\operatorname{Prp}_{12,39-20,97)}\right.$ e menores proporções de andradita $\left(\mathrm{Adr}_{1,21-9,00}\right)$ e espessartita $\left(\mathrm{Sps}_{1,40-2,90}\right)$. Os perfis composicionais apresentam-se geralmente planos (quase retos), com pequenas variações nas bordas, definidas por leve aumento de $\mathrm{Fe}^{2+}$ e leve diminuição de Ca. As concentrações de piropo e espessartita são homogêneas ao longo de todos os cristais e as concentrações de andradita mostram fraca diminuição em direção às bordas (Figura 5A, B, C). Raros cristais apresentam zoneamento, definido do núcleo para a borda, pelo 
enriquecimento em Ca (seguido por uma diminuição na borda) e diminuição dos teores de $\mathrm{Mg}$ e $\mathrm{Fe}^{2+}$ (seguido por um aumento na borda) (Figura 5D).
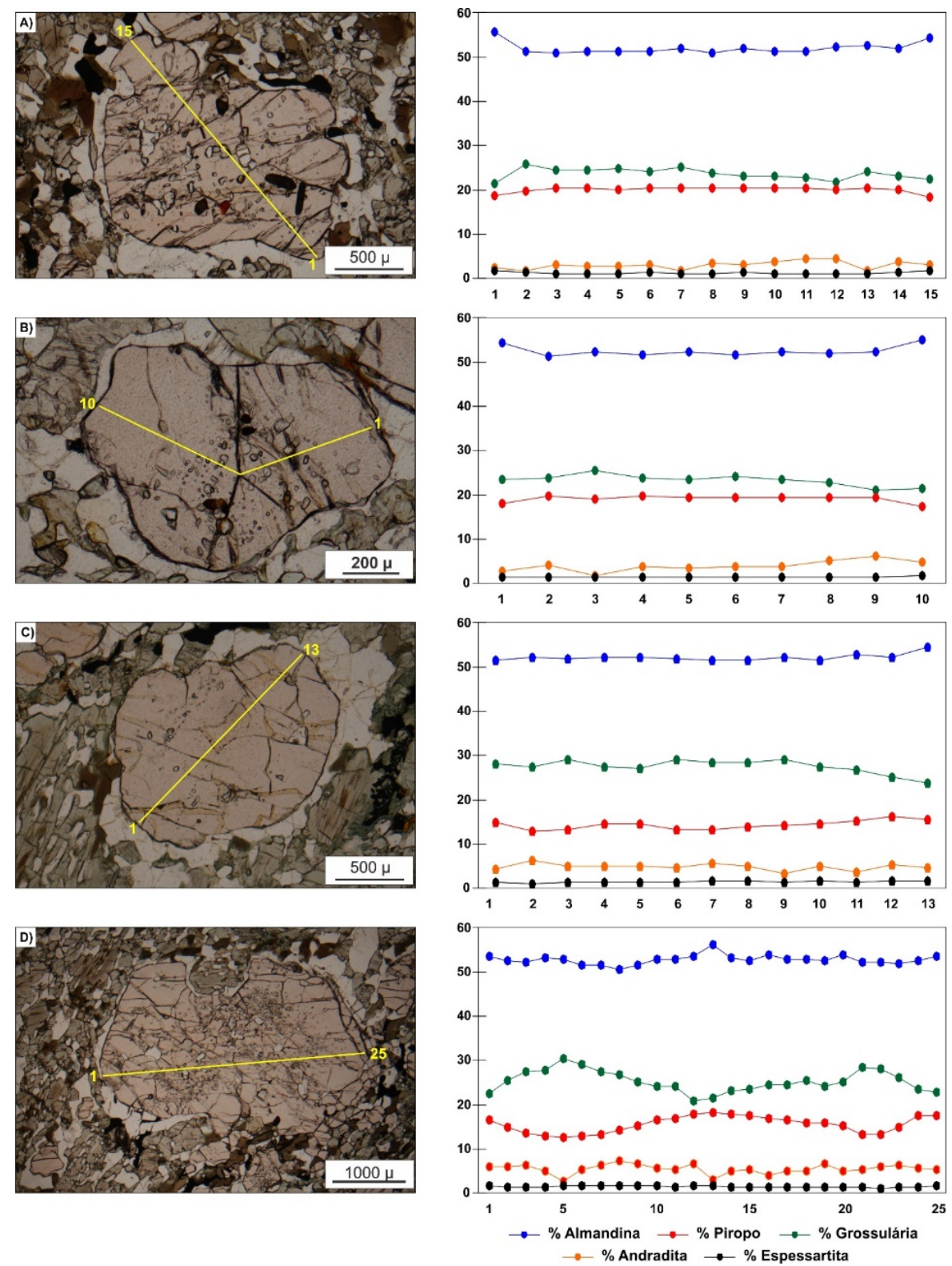

Figura 5 - A-D): Perfis composicionais de cristais de granada em amostra de retroeclogito do Grupo Araxá.

\section{Clinopiroxênio}

Os cristais de clinopiroxênio analisados são classificados como sahlita $\left(\mathrm{Wo}_{43,63-48,30} \mathrm{En}_{29,99-}\right.$ ${ }_{34,61} \mathrm{Fs}_{17,67-23,79}$ ) (Figura 6A), com teores de Ca variando de 0,786 a 0,892 átomos por unidade de fórmula (a.p.u.f.), de $\mathrm{Mg}$ entre 0,544 e 0,633 a.p.u.f., de $\mathrm{Fe}^{2+}$ variando entre 0,320 e 0,425 a.p.u.f. e conteúdo de $\mathrm{X}_{\mathrm{Mg}}$ entre 0,580 e 0,663. Apresentam conteúdos de $\mathrm{Al}$ variando de 0,097 a 0,232 a.p.u.f. e de Na variando entre 0,042 e 0,075 a.p.u.f. $\left(\mathrm{Jd}_{4,104-6,658}\right)$, mostrando correlação positiva entre esses teores (Figura 6B). Os cristais com textura simplectítica mostram os menores teores de $\mathrm{Al}$ e $\mathrm{Na}$.

\section{Anfibólio}

Os cristais de anfibólio analisados apresen- tam composição cálcica $\left(\mathrm{Ca}_{\mathrm{B}} \geq 1,5, \mathrm{Na}_{\mathrm{A}}+\mathrm{K}_{\mathrm{A}} \geq\right.$ $0,5, \mathrm{Ti} \leq 0,5$ e $\mathrm{Si}<6,5)$ e são classificados como magnésio-hastingsita no diagrama de Leake et al. (1997) (Figura 6C). Mostram conteúdos de Ti variando entre 0,192 e 0,262 a.p.u.f., de $\mathrm{Al}^{\mathrm{IV}}$ entre 1,401 e 1,627 a.p.u.f. e de $\mathrm{Al}^{\mathrm{VI}}$ entre 0,536 e 0,621 a.p.u.f. O conteúdo de Si varia de 6,373 a 6,599 a.p.u.f., o de Ca de 1,782 a 1,885 a.p.u.f., o de Mg de 1,817 a 2,517 a.p.u.f., de $\mathrm{Fe}^{2+}$ de 2,045 a 2,448 a.p.u.f. e o de $\mathrm{Na}_{\mathrm{B}}$ de 0,063 a 0,116 a.p.u.f. Os teores de $\mathrm{Na}_{\mathrm{A}}$ são relativamente altos, de 0,399 a 0,559 a.p.u.f. e os de $\mathrm{K}$ são relativamente baixos, de 0,091 a 0,118 a.p.u.f. Os cristais mostram leve enriquecimento de $\mathrm{Al}$ em direção às bordas. 


\section{Plagioclásio}

Os cristais de plagioclásio analisados apresentam composição variando entre oligoclásio e andesina $\left(\mathrm{An}_{20,72-33,81}\right)$ (Figura 6D), predominando cristais com composi- ção de oligoclásio. Mostram teores de $\mathrm{Na}$ variando de 0,637 a 0,783 a.p.u.f., de $\mathrm{Ca}$ entre 0,206 e 0,328 a.p.u.f., de $\mathrm{K}$ de 0,002 a 0,007 a.p.u.f. e de $\mathrm{Fe}^{3+}$ entre 0,001 e 0,008 a.p.u.f.

Tabela 1 - Análises químicas por microssonda eletrônica em cristais de granada e proporção molecular dos cristais analisados. Os átomos por unidade de fórmula (a.p.u.f.) foram calculados na base para 12 oxigênios.

\begin{tabular}{|c|c|c|c|c|c|c|c|c|c|c|c|c|c|c|}
\hline \multirow{2}{*}{$\begin{array}{c}\text { Amostra } \\
\text { Análise }\end{array}$} & \multicolumn{6}{|c|}{ TGL-38 } & \multicolumn{8}{|c|}{ TGL-39 } \\
\hline & 1_1 & 1_3 & 1_4 & 1_5 & 1_6 & 1_8 & 2_1 & 2_3 & $2 \_4$ & 2_5 & 2_6 & 2_7 & $2 \_8$ & 2_10 \\
\hline Cristal & 1 & 1 & 1 & 1 & 1 & 1 & 2 & 2 & 2 & 2 & 2 & 2 & 2 & 2 \\
\hline Local & b & $\mathbf{n}$ & $\mathbf{n}$ & $\mathbf{n}$ & $\mathbf{n}$ & b & b & $\mathbf{n}$ & $\mathbf{n}$ & $\mathbf{n}$ & $\mathbf{n}$ & $\mathbf{n}$ & $\mathbf{n}$ & b \\
\hline $\mathrm{SiO}_{2}$ & 38,304 & 38,883 & 38,332 & 38,610 & 38,307 & 38,134 & 38,465 & 38,340 & 38,396 & 38,135 & 38,273 & 38,032 & 38,061 & 37,935 \\
\hline $\mathrm{TiO}_{2}$ & 0,039 & 0,056 & 0,041 & 0,043 & 0,038 & 0,037 & 0,033 & 0,107 & 0,049 & 0,038 & 0,045 & 0,039 & 0,048 & 0,058 \\
\hline $\mathbf{A l}_{2} \mathbf{O}_{3}$ & 21,132 & 21,146 & 21,515 & 21,451 & 21,213 & 21,473 & 21,159 & 21,527 & 21,448 & 21,334 & 21,342 & 21,527 & 21,163 & 21,311 \\
\hline $\mathrm{Cr}_{2} \mathrm{O}_{3}$ & 0,012 & 0,000 & 0,001 & 0,000 & 0,000 & 0,037 & 0,005 & 0,012 & 0,009 & 0,000 & $-0,006$ & 0,000 & 0,002 & 0,006 \\
\hline FeO & 27,292 & 24,693 & 24,550 & 24,393 & 24,061 & 25,032 & 25,879 & 24,530 & 24,964 & 24,978 & 24,796 & 24,954 & 25,153 & 26,346 \\
\hline MnO & 0,966 & 0,580 & 0,577 & 0,527 & 0,566 & 0,682 & 0,643 & 0,612 & 0,588 & 0,590 & 0,575 & 0,599 & 0,599 & 0,745 \\
\hline MgO & 4,350 & 5,205 & 5,144 & 5,190 & 5,279 & 4,696 & 4,644 & 4,943 & 5,063 & 4,947 & 4,961 & 4,976 & 4,919 & 4,393 \\
\hline $\mathrm{CaO}$ & 8,014 & 9,945 & 9,921 & 9,906 & 10,232 & 9,717 & 9,471 & 9,823 & 9,860 & 9,675 & 9,988 & 9,614 & 9,873 & 9,273 \\
\hline $\mathrm{Na}_{2} \mathrm{O}$ & 0,000 & 0,000 & 0,000 & 0,000 & 0,000 & 0,009 & 0,009 & 0,002 & 0,000 & 0,006 & 0,016 & 0,000 & 0,003 & 0,029 \\
\hline $\mathbf{K}_{2} \mathbf{O}$ & 0,000 & 0,000 & 0,014 & 0,000 & 0,009 & 0,000 & 0,000 & 0,002 & 0,006 & 0,014 & 0,000 & 0,000 & 0,005 & 0,000 \\
\hline Total & 00,096 & 00,477 & 00,093 & 00,097 & 99,688 & 99,812 & 100,304 & 99,898 & 00,381 & 99,703 & 99,989 & 99,721 & 99,824 & 00,087 \\
\hline Si & 3,006 & 3,009 & 2,977 & 2,996 & 2,983 & 2,979 & 2,997 & 2,986 & 2,977 & 2,979 & 2,979 & 2,968 & 2,971 & 2,967 \\
\hline $\mathbf{A l}^{\mathrm{IV}}$ & 0,000 & 0,000 & 0,023 & 0,004 & 0,017 & 0,021 & 0,003 & 0,014 & 0,023 & 0,021 & 0,021 & 0,032 & 0,029 & 0,033 \\
\hline Soma & 3,006 & 3,009 & 3,000 & 3,000 & 3,000 & 3,000 & 3,000 & 3,000 & 3,000 & 3,000 & 3,000 & 3,000 & 3,000 & 3,000 \\
\hline $\mathbf{A l}^{\mathrm{VI}}$ & 1,953 & 1,927 & 1,944 & 1,956 & 1,928 & 1,954 & 1,938 & 1,961 & 1,935 & 1,941 & 1,935 & 1,947 & 1,917 & 1,930 \\
\hline $\mathbf{T i}$ & 0,002 & 0,003 & 0,002 & 0,003 & 0,002 & 0,002 & 0,002 & 0,006 & 0,003 & 0,002 & 0,003 & 0,002 & 0,003 & 0,003 \\
\hline $\mathrm{Fe}^{3+}$ & 0,024 & 0,043 & 0,068 & 0,037 & 0,080 & 0,056 & 0,057 & 0,034 & 0,076 & 0,071 & 0,078 & 0,075 & 0,101 & 0,094 \\
\hline $\mathrm{Cr}$ & 0,001 & 0,000 & 0,000 & 0,000 & 0,000 & 0,002 & 0,000 & 0,001 & 0,001 & 0,000 & 0,000 & 0,000 & 0,000 & 0,000 \\
\hline Soma & 1,980 & 1,973 & 2,015 & 1,996 & 2,009 & 2,014 & 1,997 & 2,002 & 2,014 & 2,014 & 2,015 & 2,024 & 2,021 & 2,028 \\
\hline $\mathrm{Fe}^{2+}$ & 1,767 & 1,555 & 1,526 & 1,546 & 1,487 & 1,579 & 1,629 & 1,564 & 1,543 & 1,560 & 1,536 & 1,554 & 1,541 & 1,629 \\
\hline Mn & 0,064 & 0,038 & 0,038 & 0,035 & 0,037 & 0,045 & 0,042 & 0,040 & 0,039 & 0,039 & 0,038 & 0,040 & 0,040 & 0,049 \\
\hline Mg & 0,509 & 0,600 & 0,595 & 0,600 & 0,613 & 0,547 & 0,539 & 0,574 & 0,585 & 0,576 & 0,576 & 0,579 & 0,572 & 0,512 \\
\hline Ca & 0,674 & 0,825 & 0,825 & 0,824 & 0,854 & 0,813 & 0,791 & 0,820 & 0,819 & 0,810 & 0,833 & 0,804 & 0,826 & 0,777 \\
\hline $\mathbf{N a}$ & 0,000 & 0,000 & 0,000 & 0,000 & 0,000 & 0,001 & 0,001 & 0,000 & 0,000 & 0,001 & 0,002 & 0,000 & 0,000 & 0,004 \\
\hline Soma & 3,014 & 3,018 & 2,985 & 3,004 & 2,991 & 2,986 & 3,003 & 2,998 & 2,986 & 2,986 & 2,985 & 2,976 & 2,979 & 2,972 \\
\hline$\Sigma$ Cátions & 8,000 & 8,000 & 8,000 & 8,000 & 8,000 & 8,000 & 8,000 & 8,000 & 8,000 & 8,000 & 8,000 & 8,000 & 8,000 & 8,000 \\
\hline Alm & 58,63 & 51,52 & 51,13 & 51,45 & 49,72 & 52,89 & 54,26 & 52,16 & 51,68 & 52,26 & 51,46 & 52,21 & 51,73 & 54,81 \\
\hline Pyp & 16,89 & 19,90 & 19,95 & 19,98 & 20,49 & 18,32 & 17,96 & 19,14 & 19,60 & 19,29 & 19,29 & 19,45 & 19,21 & 17,24 \\
\hline Grs & 21,11 & 25,14 & 24,26 & 25,55 & 24,58 & 24,34 & 23,47 & 25,60 & 23,64 & 23,58 & 24,05 & 23,31 & 22,72 & 21,47 \\
\hline And & 1,21 & 2,19 & 3,39 & 1,86 & 3,97 & 2,78 & 2,84 & 1,70 & 3,76 & 3,54 & 3,87 & 3,70 & 4,99 & 4,66 \\
\hline Sps & 2,13 & 1,26 & 1,27 & 1,15 & 1,25 & 1,51 & 1,41 & 1,35 & 1,29 & 1,31 & 1,27 & 1,33 & 1,33 & 1,66 \\
\hline Uvr & 0,04 & 0,00 & 0,00 & 0,00 & 0,00 & 0,11 & 0,02 & 0,04 & 0,03 & 0,00 & 0,02 & 0,00 & 0,01 & 0,02 \\
\hline
\end{tabular}

\section{GEOTERMOBAROMETRIA}

\section{Average P-T}

Os cálculos de Average P-T (Powell \& Holland, 1994) foram realizados com o software THERMOCALC 3.26.

Para os cálculos, utilizou-se a associação mineral sahlita + almandina + Mg-hastingsita + andesina/oligoclásio + quartzo, com atividade de $\mathrm{CO}_{2}\left(\mathrm{a}_{\mathrm{CO} 2}\right)$ igual a 0,7 .

Os resultados calculados são apresentados na tabela 5. 
Tabela 2 - Análises químicas por microssonda eletrônica em cristais de piroxênio. Os átomos por unidade de fórmula (a.p.u.f.) foram calculados na base para 6 oxigênios.

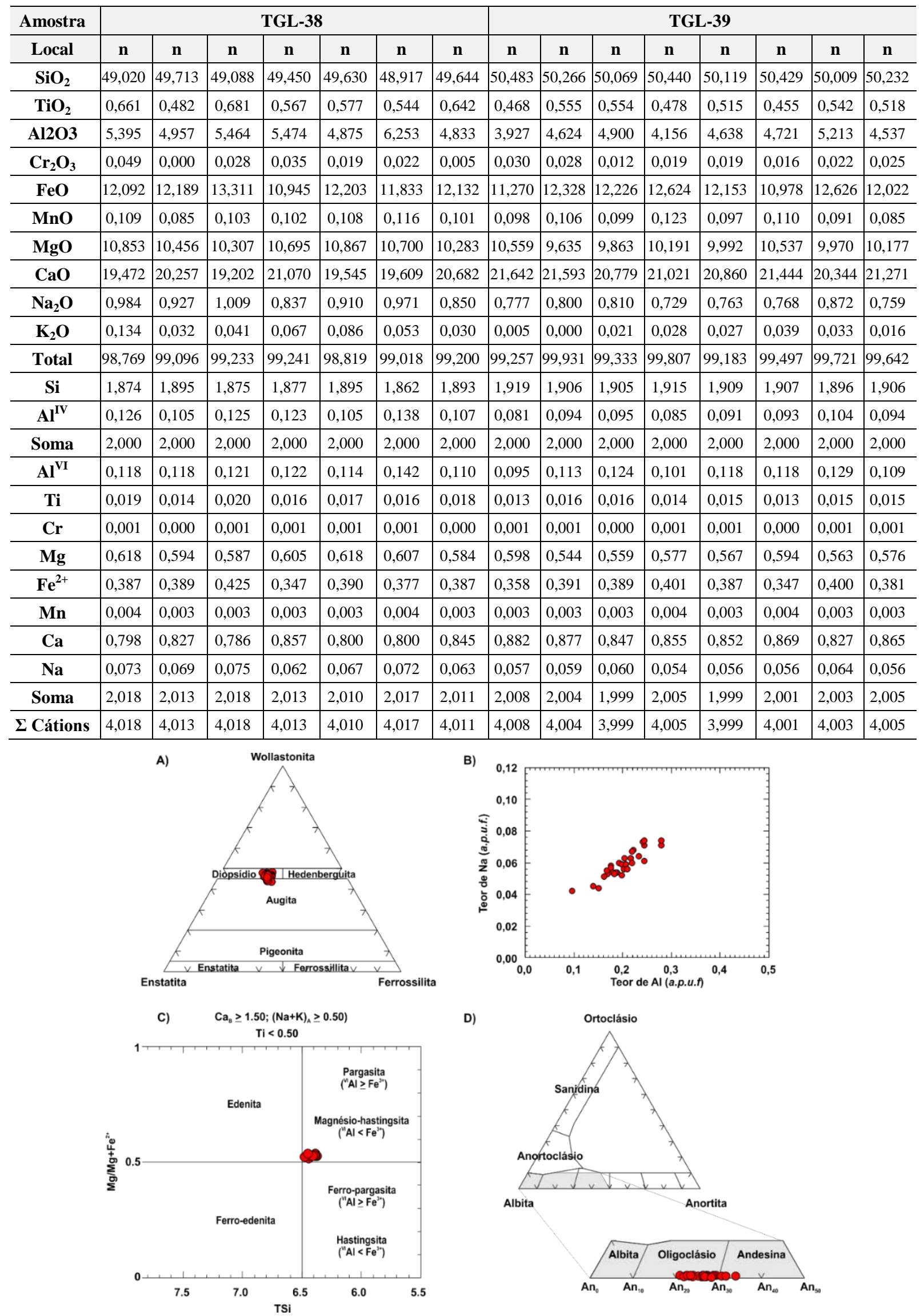

Figura 6 - (A): Diagrama ternário Ca-Mg-Fe para classificação de piroxênios (Morimoto, 1988); (B): Diagrama binário $\mathrm{Al}$ (em a.p.u.f.) x Na (em a.p.u.f.) para cristais de piroxênio em amostras de retroeclogito; (C): Diagrama de classificação de anfibólios cálcicos (Modificado de Leake et al., 1997) para cristais de anfibólio de amostras de retroeclogito; (D): Diagrama ternário de classificação de feldspatos. 
Tabela 3 - Análises químicas por microssonda eletrônica em cristais de anfibólio. Os átomos por unidade de fórmula (a.p.u.f.) foram calculados na base de 23 oxigênios.

\begin{tabular}{|c|c|c|c|c|c|c|c|c|c|c|c|}
\hline Amostra & & & & TGL-38 & & & & & TG & -39 & \\
\hline Local & $\mathbf{n}$ & $\mathbf{n}$ & $\mathbf{n}$ & $\mathbf{n}$ & $\mathbf{n}$ & $\mathbf{n}$ & $\mathbf{n}$ & $\mathbf{n}$ & $\mathbf{n}$ & n & $\mathbf{n}$ \\
\hline $\mathrm{SiO}_{2}$ & 42,512 & 42,415 & 42,461 & 42,642 & 42,658 & 42,460 & 42,563 & 42,366 & 43,572 & 42,886 & 42,632 \\
\hline $\mathrm{TiO}_{2}$ & 2,207 & 2,207 & 2,166 & 2,315 & 2,262 & 2,140 & 2,221 & 2,036 & 1,685 & 1,805 & 1,898 \\
\hline $\mathrm{Al}_{2} \mathbf{O}_{3}$ & 11,859 & 12,291 & 12,442 & 11,976 & 12,552 & 12,075 & 12,143 & 11,788 & 11,039 & 11,633 & 12,080 \\
\hline $\mathrm{Cr}_{2} \mathrm{O}_{3}$ & 0,070 & 0,048 & 0,061 & 0,043 & 0,044 & 0,027 & 0,074 & 0,035 & 0,025 & 0,017 & 0,021 \\
\hline FeO & 16,346 & 16,331 & 16,779 & 16,233 & 16,363 & 16,390 & 16,529 & 18,564 & 19,328 & 17,238 & 16,549 \\
\hline MnO & 0,089 & 0,106 & 0,100 & 0,095 & 0,049 & 0,089 & 0,082 & 0,141 & 0,165 & 0,085 & 0,089 \\
\hline MgO & 9,547 & 9,795 & 9,617 & 9,684 & 9,712 & 9,817 & 9,670 & 8,427 & 8,049 & 9,540 & 9,638 \\
\hline $\mathrm{CaO}$ & 11,527 & 11,153 & 11,243 & 11,393 & 11,416 & 11,553 & 11,365 & 11,140 & 11,617 & 11,164 & 10,971 \\
\hline $\mathrm{Na}_{2} \mathrm{O}$ & 2,105 & 2,257 & 2,204 & 2,189 & 2,233 & 2,177 & 2,150 & 1,829 & 1,573 & 1,953 & 1,904 \\
\hline $\mathbf{K}_{2} \mathbf{O}$ & 0,542 & 0,479 & 0,544 & 0,486 & 0,554 & 0,531 & 0,499 & 0,609 & 0,559 & 0,473 & 0,534 \\
\hline Total & 96,802 & 97,081 & 97,618 & 97,056 & 97,842 & 97,259 & 97,295 & 96,935 & 97,612 & 96,793 & 96,314 \\
\hline Si & 6,428 & 6,387 & 6,373 & 6,422 & 6,374 & 6,393 & 6,402 & 6,454 & 6,599 & 6,492 & 6,463 \\
\hline $\mathbf{A l}^{\mathbf{I V}}$ & 1,572 & 1,613 & 1,627 & 1,578 & 1,626 & 1,607 & 1,598 & 1,546 & 1,401 & 1,508 & 1,537 \\
\hline Soma & 8,000 & 8,000 & 8,000 & 8,000 & 8,000 & 8,000 & 8,000 & 8,000 & 8,000 & 8,000 & 8,000 \\
\hline $\mathrm{Al}^{\mathrm{VI}}$ & 0,542 & 0,569 & 0,575 & 0,548 & 0,586 & 0,536 & 0,555 & 0,571 & 0,570 & 0,568 & 0,621 \\
\hline $\mathbf{T i}$ & 0,251 & 0,250 & 0,244 & 0,262 & 0,254 & 0,242 & 0,251 & 0,233 & 0,192 & 0,205 & 0,216 \\
\hline $\mathrm{Cr}$ & 0,008 & 0,006 & 0,007 & 0,005 & 0,005 & 0,003 & 0,009 & 0,004 & 0,003 & 0,002 & 0,003 \\
\hline Mg & 2,151 & 2,198 & 2,151 & 2,174 & 2,163 & 2,203 & 2,168 & 1,913 & 1,817 & 2,152 & 2,177 \\
\hline $\mathrm{Fe}^{2+}$ & 2,047 & 1,977 & 2,022 & 2,011 & 1,992 & 2,016 & 2,017 & 2,279 & 2,418 & 2,073 & 1,982 \\
\hline Soma & 5,000 & 5,000 & 5,000 & 5,000 & 5,000 & 5,000 & 5,000 & 5,000 & 5,000 & 5,000 & 5,000 \\
\hline $\mathrm{Fe}^{2+}$ & 0,020 & 0,080 & 0,084 & 0,033 & 0,053 & 0,048 & 0,062 & 0,086 & 0,030 & 0,110 & 0,116 \\
\hline Mn & 0,011 & 0,013 & 0,013 & 0,012 & 0,006 & 0,011 & 0,010 & 0,018 & 0,021 & 0,011 & 0,011 \\
\hline Ca & 1,868 & 1,800 & 1,808 & 1,838 & 1,828 & 1,864 & 1,832 & 1,818 & 1,885 & 1,811 & 1,782 \\
\hline $\mathrm{Na}$ & 0,101 & 0,107 & 0,095 & 0,116 & 0,113 & 0,077 & 0,096 & 0,077 & 0,063 & 0,069 & 0,091 \\
\hline Soma 6 & 2,000 & 2,000 & 2,000 & 2,000 & 2,000 & 2,000 & 2,000 & 2,000 & 2,000 & 2,000 & 2,000 \\
\hline $\mathrm{Na}$ & 0,516 & 0,552 & 0,546 & 0,523 & 0,534 & 0,559 & 0,531 & 0,463 & 0,399 & 0,504 & 0,469 \\
\hline $\mathbf{K}$ & 0,105 & 0,092 & 0,104 & 0,093 & 0,106 & 0,102 & 0,096 & 0,118 & 0,108 & 0,091 & 0,103 \\
\hline Soma 1 & 0,620 & 0,644 & 0,651 & 0,617 & 0,639 & 0,661 & 0,627 & 0,582 & 0,507 & 0,596 & 0,572 \\
\hline$\Sigma$ Cátions & 15,620 & 15,644 & 15,651 & 15,617 & 15,639 & 15,661 & 15,627 & 15,582 & 15,507 & 15,596 & 15,572 \\
\hline
\end{tabular}

Os valores de condições $P-T$, para as variáveis calculadas simultaneamente, resultam

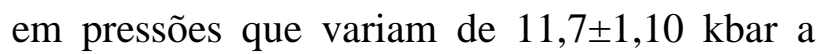
$12,5 \pm 1,10$ kbar e temperaturas que variam de $724 \pm 48^{\circ} \mathrm{C}$ a $799 \pm 37^{\circ} \mathrm{C}$, com valores de correlação baixos, variando de 0,20 a 0,30 (Figura 7A, Tabela 5).

Os resultados de pressão calculados separadamente são menos homogêneos quando comparado aos valores de pressão calculados junto da temperatura, e variam de 10,58 $\pm 0,60$ kbar a 12,9 $\pm 0,48$ (Tabela 5).

Já os valores de temperatura calculados separadamente são correspondentes aos calculados em conjunto com a pressão, variando de $735 \pm 33^{\circ} \mathrm{C}$ a $808 \pm 50^{\circ} \mathrm{C}$ (Tabela 5).

Não foi possível calcular valores de pressão e temperatura quando o anfibólio é excluído da associação mineral, sugerindo que este está em equilíbrio.

\section{Zr-em-Rutilo}

A concentração de $\mathrm{Zr}$ em rutilo é fortemente dependente da temperatura e da atividade de Si, e tem sido utilizada como um geotermômetro em rochas com associação mineral contendo rutilo, zircão e quartzo em equilíbrio (Zack et al., 2004; Watson et al., 2006; Tomkins et al., 2007).

Neste trabalho, foi utilizada a calibração de Tomkins et al. (2007), que assume um efeito secundário da pressão que acompanha a dependência primária da temperatura no conteúdo de Zr em rutilo.

As concentrações de $\mathrm{Zr}$ em cristais de rutilo analisados e as respectivas temperaturas calculadas pelo geotermômetro são apresentados na tabela 6. 
Tabela 4 - Análises químicas por microssonda eletrônica em cristais de plagioclásio. Os átomos por unidade de fórmula (a.p.u.f.) foram calculados na base de 8 oxigênios.

\begin{tabular}{|c|c|c|c|c|c|c|c|c|c|c|c|c|c|c|}
\hline \multirow{2}{*}{$\frac{\text { Amostra }}{\text { Local }}$} & \multicolumn{7}{|c|}{ TGL-38 } & \multicolumn{7}{|c|}{ TGL-39 } \\
\hline & n & n & $\mathbf{n}$ & $\mathbf{n}$ & n & n & $\mathbf{n}$ & $\mathbf{n}$ & $\mathbf{n}$ & b & $\mathbf{n}$ & b & $\mathbf{n}$ & $\mathbf{n}$ \\
\hline $\mathrm{SiO}_{2}$ & 59,623 & 60,689 & 60,012 & 62,117 & 62,048 & 60,809 & 60,361 & 61,361 & 62,167 & 60,942 & 61,874 & 61,115 & 60,345 & 62,814 \\
\hline $\mathbf{A l}_{2} \mathbf{O}_{3}$ & 25,813 & 24,949 & 24,991 & 23,861 & 24,156 & 25,158 & 25,452 & 24,566 & 23,924 & 24,787 & 24,014 & 24,817 & 25,158 & 23,741 \\
\hline $\mathrm{Fe}_{2} \mathrm{O}_{3}$ & 0,184 & 0,115 & 0,104 & 0,059 & 0,059 & 0,134 & 0,052 & 0,167 & 0,036 & 0,093 & 0,048 & 0,107 & 0,252 & 0,056 \\
\hline $\mathrm{BaO}$ & 0,000 & 0,003 & 0,000 & 0,000 & 0,000 & 0,000 & 0,000 & 0,000 & 0,002 & 0,013 & 0,000 & 0,006 & 0,000 & 0,000 \\
\hline $\mathrm{CaO}$ & 6,881 & 5,654 & 6,118 & 4,522 & 4,920 & 5,900 & 6,224 & 5,495 & 4,579 & 5,492 & 4,979 & 5,785 & 5,912 & 4,357 \\
\hline $\mathrm{Na}_{2} \mathrm{O}$ & 7,382 & 8,275 & 8,129 & 8,815 & 8,809 & 8,130 & 7,800 & 8,517 & 9,030 & 8,348 & 8,775 & 8,120 & 8,213 & 9,145 \\
\hline $\mathrm{K}_{2} \mathrm{O}$ & 0,094 & 0,099 & 0,101 & 0,089 & 0,087 & 0,100 & 0,083 & 0,061 & 0,077 & 0,057 & 0,070 & 0,041 & 0,082 & 0,106 \\
\hline Total & 99,966 & 99,784 & 99,422 & 99,427 & 100,067 & 100,193 & 99,972 & 100,153 & 99,814 & 99,731 & 99,707 & 99,992 & 99,945 & 100,214 \\
\hline $\mathrm{Si}$ & 2,654 & 2,701 & 2,685 & 2,762 & 2,746 & 2,695 & 2,682 & 2,719 & 2,757 & 2,711 & 2,748 & 2,711 & 2,685 & 2,772 \\
\hline $\mathbf{A l}^{\mathrm{IV}}$ & 1,355 & 1,309 & 1,318 & 1,251 & 1,260 & 1,314 & 1,333 & 1,283 & 1,251 & 1,300 & 1,257 & 1,298 & 1,320 & 1,235 \\
\hline Soma & 4,009 & 4,010 & 4,003 & 4,012 & 4,007 & 4,009 & 4,015 & 4,002 & 4,008 & 4,011 & 4,005 & 4,009 & 4,004 & 4,007 \\
\hline $\mathrm{Fe}^{3+}$ & 0,006 & 0,004 & 0,004 & 0,002 & 0,002 & 0,004 & 0,002 & 0,006 & 0,001 & 0,003 & 0,002 & 0,004 & 0,008 & 0,002 \\
\hline $\mathbf{B a}$ & 0,000 & 0,000 & 0,000 & 0,000 & 0,000 & 0,000 & 0,000 & 0,000 & 0,000 & 0,000 & 0,000 & 0,000 & 0,000 & 0,000 \\
\hline $\mathrm{Ca}$ & 0,328 & 0,270 & 0,293 & 0,215 & 0,233 & 0,280 & 0,296 & 0,261 & 0,218 & 0,262 & 0,237 & 0,275 & 0,282 & 0,206 \\
\hline $\mathrm{Na}$ & 0,637 & 0,714 & 0,705 & 0,760 & 0,756 & 0,699 & 0,672 & 0,732 & 0,776 & 0,720 & 0,755 & 0,698 & 0,708 & 0,783 \\
\hline $\mathbf{K}$ & 0,005 & 0,006 & 0,006 & 0,005 & 0,005 & 0,006 & 0,005 & 0,003 & 0,004 & 0,003 & 0,004 & 0,002 & 0,005 & 0,006 \\
\hline Soma & 0,977 & 0,993 & 1,008 & 0,982 & 0,996 & 0,989 & 0,975 & 1,002 & 1,000 & 0,988 & 0,998 & 0,979 & 1,003 & 0,996 \\
\hline$\Sigma$ Cátions & 4,986 & 5,003 & 5,010 & 4,995 & 5,003 & 4,998 & 4,989 & 5,004 & 5,007 & 4,999 & 5,003 & 4,988 & 5,008 & 5,004 \\
\hline $\mathbf{A b}$ & 65,64 & 72,18 & 70,22 & 77,51 & 76,04 & 70,96 & 69,06 & 73,46 & 77,77 & 73,10 & 75,82 & 71,58 & 71,21 & 78,68 \\
\hline An & 33,81 & 27,25 & 29,20 & 21,97 & 23,47 & 28,46 & 30,45 & 26,19 & 21,79 & 26,58 & 23,78 & 28,18 & 28,33 & 20,72 \\
\hline Or & 0,55 & 0,57 & 0,58 & 0,52 & 0,49 & 0,58 & 0,48 & 0,35 & 0,44 & 0,33 & 0,40 & 0,24 & 0,47 & 0,60 \\
\hline Total & 100,00 & 100,00 & 100,00 & 100,00 & 100,00 & 100,00 & 100,00 & 100,00 & 100,00 & 100,00 & 100,00 & 100,00 & 100,00 & 100,00 \\
\hline
\end{tabular}

Tabela 5 - Condições $P-T$ calculadas pelo software THERMOCALC para amostras de retroeclogito.

\begin{tabular}{c|c|c|c|c}
\hline Associação & Average P-T (Kbar e $\left.{ }^{\mathbf{O}} \mathbf{C}\right)$ & Cor. & P (Kbar) & T $\left({ }^{\circ} \mathbf{C}\right)$ \\
\hline $\mathbf{c p x}+\mathbf{g r t}+\mathbf{a m p h}+\mathbf{p l}+\mathbf{q t z}$ & $11,8 \pm 0,70 / 756 \pm 30$ & 0,220 & $11,35 \pm 0,85$ & $754 \pm 35$ \\
$\mathbf{c p x}+\mathbf{g r t}+\mathbf{a m p h}+\mathbf{p l}+\mathbf{q t z}$ & $12,0 \pm 0,90 / 749 \pm 39$ & 0,217 & $11,76 \pm 0,82$ & $748 \pm 43$ \\
$\mathbf{c p x}+\mathbf{g r t}+\mathbf{a m p h}+\mathbf{p l}+\mathbf{q t z}$ & $12,5 \pm 0,70 / 772 \pm 33$ & 0,222 & $12,33 \pm 0,49$ & $808 \pm 50$ \\
$\mathbf{c p x}+\mathbf{g r t}+\mathbf{a m p h}+\mathbf{p l}+\mathbf{q t z}$ & $12,5 \pm 1,10 / 757 \pm 49$ & 0,298 & $12,30 \pm 0,48$ & $735 \pm 33$ \\
$\mathbf{c p x}+\mathbf{g r t}+\mathbf{a m p h}+\mathbf{p l}+\mathbf{q t z}$ & $11,7 \pm 1,10 / 724 \pm 48$ & 0,236 & $12,90 \pm 0,48$ & $766 \pm 54$ \\
$\mathbf{c p x}+\mathbf{g r t}+\mathbf{a m p h}+\mathbf{p l}+\mathbf{q t z}$ & $12,5 \pm 0,80 / 799 \pm 37$ & 0,308 & $10,58 \pm 0,60$ & $796 \pm 29$ \\
\hline
\end{tabular}
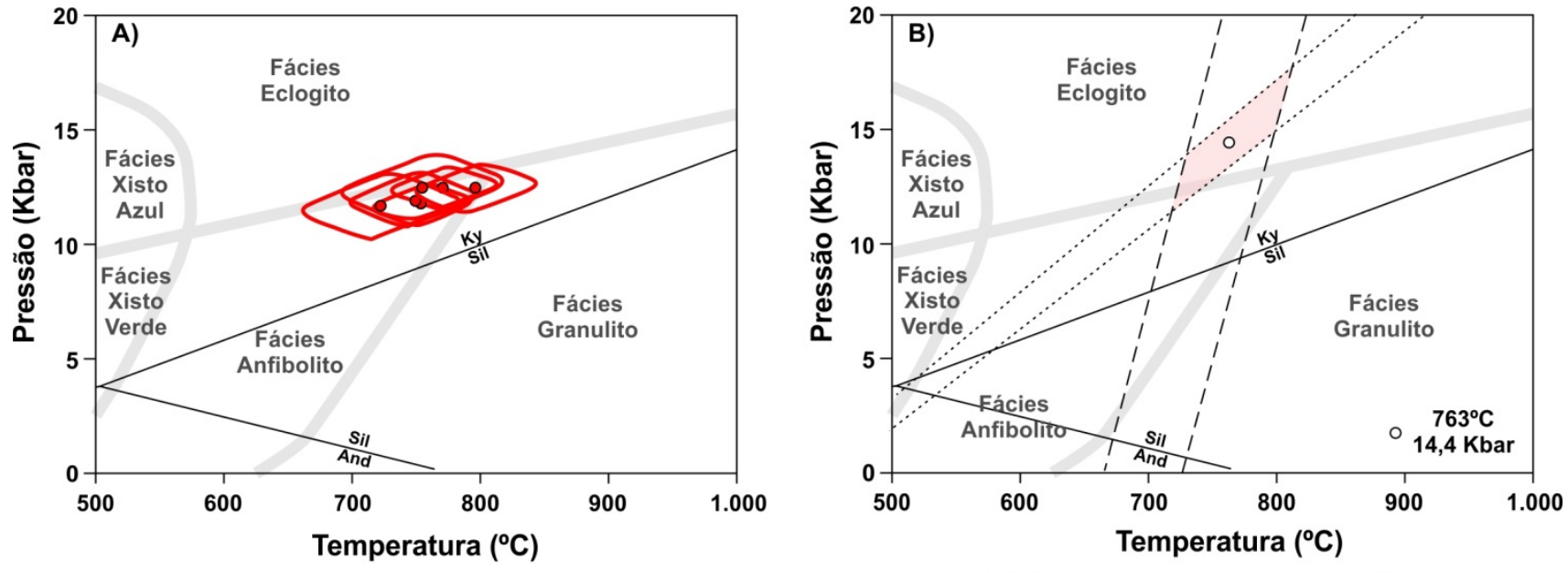

… Ti em quartzo

- - Zr em rutilo

Figura 7 - (A): Diagrama $P-T$ mostrando as condições de pressão e temperatura calculadas com o software THERMOCALC (Average P-T) para as amostras de retroeclogito; (B): Diagramas P-T mostrando o cálculo pareado dos geotermômetros Zr-em-rutilo (Tomkins et al., 2007) e Ti-em-quartzo (Thomas et al., 2010) para as amostras de retroeclogito. (Diagrama de fácies metamórficas modificado de Spear, 1993). 
Tabela 6 - Teores de Zr (em ppm) em cristais de rutilo em amostra de retroeclogito e temperaturas calculadas utilizando o termômetro Zr-em-rutilo de Tomkins et al. (2007) para o campo do quartzo- $\beta$ para pressões fixadas em 13, 14 e 15 kbar.

\begin{tabular}{c|c|c|c|c|c}
\hline Cristal & Textura & $\mathbf{Z r}$ & $\begin{array}{c}\text { T }\left({ }^{\circ} \mathbf{C}\right)- \\
\mathbf{1 3 ~ k b a r}\end{array}$ & $\begin{array}{c}\text { T }\left({ }^{\circ} \mathbf{C}\right) \\
\mathbf{1 4} \mathbf{k b a r}\end{array}$ & $\begin{array}{c}\mathbf{T}\left({ }^{\circ} \mathbf{C}\right) \\
\mathbf{1 5} \mathbf{k b a r}\end{array}$ \\
\hline rt_1 & Inclusão & 944 & 767 & 772 & 777 \\
\hline rt_2 & Inclusão & 828 & 754 & 759 & 765 \\
\hline rt_3 & Inclusão & 947 & 767 & 772 & 778 \\
\hline rt_4 & Inclusão & 950 & 767 & 773 & 778 \\
\hline rt_5 & Inclusão & 961 & 768 & 774 & 779 \\
\hline rt_6 & Inclusão & 1.109 & 783 & 788 & 794 \\
\hline rt_8 & Inclusão & 1.171 & 788 & 794 & 799 \\
\hline rt_9 & Inclusão & 812 & 752 & 757 & 763 \\
\hline rt_10 & Inclusão & 720 & 741 & 746 & 751 \\
\hline rt_11 & Inclusão & 939 & 766 & 771 & 777 \\
\hline rt_12 & Inclusão & 640 & 730 & 735 & 740 \\
\hline rt_13 & Inclusão & 734 & 743 & 748 & 753 \\
\hline rt_14 & Inclusão & 752 & 745 & 750 & 755 \\
\hline rt_15 & Inclusão & 1.142 & 786 & 791 & 796 \\
\hline rt_16 & Inclusão & 942 & 766 & 772 & 777 \\
\hline rt_17 & Inclusão & 930 & 765 & 771 & 776 \\
\hline
\end{tabular}

$\mathrm{Na}$ amostra de retroeclogito, foram analisados cristais de rutilo inclusos em cristais de granada, e o conteúdo de $\mathrm{Zr}$ varia de 640 a 1.171 ppm. Os cálculos para o geotermômetro de Zr-em-rutilo, para pressões de 13, 14 e 15 kbar, para o campo de estabilidade do quartzo$\beta$, resultam em temperaturas que variam de 730 a $788^{\circ} \mathrm{C}$, de 735 a $794^{\circ} \mathrm{C}$ e de 740 a $799^{\circ} \mathrm{C}$, respectivamente. Não foram observadas diferenças nas temperaturas calculadas em relação à posição do cristal de rutilo (borda e núcleo) inclusos em granada.

\section{Ti-em-Quartzo}

Diversos estudos experimentais quantificaram a dependência da temperatura e da pressão na solubilidade do $\mathrm{Ti}$ em quartzo (Wark \& Watson, 2006; Ostapenko et al., 2007; Thomas et al., 2010; Huang \& Audétat, 2012; Thomas et al., 2015). Quando em presença de minerais de titânio, especialmente rutilo, o Ti pode substituir o $\mathrm{Si}$ na estrutura do quartzo devido à natureza tetravalente desses cátions, sem que seja necessário o balanço de cargas. $\mathrm{O}$ potencial químico do $\mathrm{Ti}$ e a extensão da substituição do Ti pelo Si no quartzo, variam sistematicamente com a temperatura e a pressão, sendo utilizados como um geotermômetro. Neste trabalho, foi utilizada a calibração de Thomas et al. (2010), que assume forte dependência da temperatura e pressão no conteúdo de Ti no quartzo. Os resultados das concentrações de elementos traço em quartzo e das respectivas temperaturas calculadas pelo geotermômetro são apresentados na tabela 7 .

Foram analisados cristais de quartzo da matriz da rocha e cristais inclusos em granada. $\mathrm{O}$ teor de $\mathrm{Ti}$ em quartzo nos cristais da matriz varia de 28 a 66 ppm e o conteúdo de Ti dos cristais inclusos em granada varia de 38 a 58 ppm. Os cálculos para o geotermômetro Ti-emquartzo, para pressões de 13, 14 e 15 kbar, resultam em temperaturas que variam de 689 a $776^{\circ} \mathrm{C}$, de 709 a $798^{\circ} \mathrm{C}$ e de 729 a $820^{\circ} \mathrm{C}$, respectivamente. Não foram observadas diferenças significativas nas temperaturas calculadas em relação aos cristais inclusos em granada e dos cristais na matriz.

\section{Isopletas}

A dependência da temperatura e da pressão na solubilidade de $\mathrm{Ti}$ no quartzo pode ser utilizada como geotermobarômetro quando combinada com geotermômetros de fases minerais coexistentes, como Zr-em-rutilo ou Zr-em-titanita, ou ainda com outros métodos termométricos e barométricos baseados em equilíbrio de fases metamórficas para estimar condições $P-T$ (Thomas et al., 2010). Para os mesmos autores, o uso do método Ti-emquartzo é mais eficiente em rochas que contêm rutilo, com atividade de $\mathrm{TiO}_{2}\left(\mathrm{a}_{\mathrm{TiO} 2}\right)$ igual a 1,0 , combinando assim os métodos de Ti-emquartzo e Zr-em-rutilo de Tomkins et al. (2007) 
para obter estimativas de pressão e temperatura. Os cálculos das isopletas foram realizados para os cristais de rutilo e quartzo inclusos em granada e mostram condições de $763^{\circ} \mathrm{C}$ e 14,4 kbar (campo de estabilidade variando de $718^{\circ} \mathrm{C}$ e 11,4 kbar a $812^{\circ} \mathrm{C}$ e 17,7 kbar) (Figura $7 \mathrm{~B}$ ).

Tabela 7 - Teores de Ti (em ppm) analisados em cristais de quartzo em amostra de retroeclogito e temperaturas calculadas utilizando o termômetro Ti-em-quartzo de Thomas et al. (2010) para pressões fixadas em 13, 14 e 15 kbar.

\begin{tabular}{|c|c|c|c|c|c|}
\hline Cristal & Textura & $\mathbf{T i}$ & $\begin{array}{l}\mathrm{T}\left({ }^{\circ} \mathrm{C}\right)- \\
13 \text { kbar }\end{array}$ & $\begin{array}{l}\mathrm{T}\left({ }^{\circ} \mathrm{C}\right) \text { - } \\
14 \text { kbar }\end{array}$ & $\begin{array}{l}\mathrm{T}\left({ }^{\circ} \mathrm{C}\right)- \\
15 \text { kbar }\end{array}$ \\
\hline qtz_1 & Inclusão & 40 & 724 & 745 & 766 \\
\hline qtz_3 & Inclusão & 38 & 718 & 739 & 760 \\
\hline qtz_4 & Inclusão & 55 & 756 & 777 & 799 \\
\hline qtz_5 & Inclusão & 53 & 752 & 774 & 795 \\
\hline qtz_6 & Inclusão & 52 & 751 & 772 & 794 \\
\hline qtz_7 & Matriz & 39 & 721 & 742 & 763 \\
\hline qtz_8 & Matriz & 52 & 751 & 772 & 794 \\
\hline qtz_9 & Inclusão & 56 & 758 & 779 & 801 \\
\hline qtz_10 & Inclusão & 44 & 733 & 754 & 775 \\
\hline qtz_11 & Matriz & 31 & 700 & 720 & 740 \\
\hline qtz_12 & Matriz & 40 & 723 & 744 & 764 \\
\hline qtz_13 & Matriz & 66 & 776 & 798 & 820 \\
\hline qtz_14 & Matriz & 37 & 715 & 736 & 756 \\
\hline qtz_15 & Matriz & 40 & 724 & 745 & 766 \\
\hline qtz_16 & Inclusão & 55 & 757 & 778 & 800 \\
\hline qtz_17 & Inclusão & 47 & 740 & 761 & 782 \\
\hline qtz_18 & Matriz & 47 & 740 & 761 & 782 \\
\hline qtz_19 & Matriz & 28 & 689 & 709 & 729 \\
\hline qtz_20 & Matriz & 49 & 745 & 766 & 787 \\
\hline qtz_21 & Matriz & 41 & 726 & 747 & 768 \\
\hline qtz_22 & Matriz & 38 & 718 & 739 & 760 \\
\hline qtz_24 & Matriz & 47 & 740 & 761 & 782 \\
\hline qtz_55 & Matriz & 44 & 734 & 755 & 776 \\
\hline qtz_26 & Matriz & 40 & 724 & 745 & 766 \\
\hline qtz_27 & Matriz & 33 & 705 & 726 & 746 \\
\hline qtz_28 & Matriz & 45 & 736 & 757 & 778 \\
\hline qtz_29 & Matriz & 46 & 738 & 759 & 781 \\
\hline qtz_30 & Matriz & 50 & 746 & 767 & 789 \\
\hline qtz_31 & Inclusão & 50 & 746 & 767 & 789 \\
\hline qtz_32 & Inclusão & 41 & 726 & 747 & 768 \\
\hline qtz_33 & Inclusão & 46 & 738 & 759 & 781 \\
\hline qtz_34 & Inclusão & 44 & 734 & 755 & 776 \\
\hline qtz_35 & Inclusão & 43 & 730 & 751 & 772 \\
\hline qtz_36 & Inclusão & 52 & 750 & 771 & 792 \\
\hline qtz_37 & Inclusão & 58 & 762 & 784 & 806 \\
\hline qtz_38 & Inclusão & 51 & 749 & 770 & 791 \\
\hline qtz_39 & Inclusão & 44 & 733 & 754 & 775 \\
\hline qtz_40 & Inclusão & 44 & 733 & 754 & 775 \\
\hline
\end{tabular}

\section{DISCUSSÕES}

O retroeclogito apresenta textura 1998; Oh \& Liou, 1998; O’Brien \& Rötzler, simplectítica, marcada pelo intercrescimento 2003; Waters, 2003; Lanari et al., 2013), lamelar de Ca-piroxênio + Na-plagioclásio originada a partir da reação sólido-sólido $\left(\mathrm{An}_{20-33}\right)$, típica de eclogitos máficos durante queda de pressão, em consequência da retrometamorfisados (O'Brien, 1989; Harley, desestabilização da onfacita: onfacita + quartzo 
$\rightarrow$ Na-plagioclásio + Ca-clinopiroxênio (Ni et al., 2006; Zhang et al., 2006; Martin, 2018).

As análises químicas em cristais de clinopiroxênio mostram conteúdos de $\mathrm{Al}$ e $\mathrm{Na}$ (em a.p.u.f.) relativamente mais elevados, que sugerem condições de pressão mais elevadas. Os menores teores $\mathrm{Al}$ e $\mathrm{Na}$ ocorrem associados aos cristais com textura simplectítica.

A forma geral dos cristais de granada, mostrando bordas lobuladas, indica corrosão desta fase mineral, que ocorreu no estágio de reequilíbrio da assembleia mineral, durante a formação dos simplectitos e das coronas.

A composição dos cristais de granada é definida pela composição química global da rocha, dominando moléculas de almandina (Alm $49,72-60,03)$ e grossulária (Grs $16,68-30,40)$, com perfis composicionais quase retos e sutis variações composicionais em direção às bordas dos cristais. Essas características químicas são comuns para rochas de alto grau metamórfico, visto que, sob condições de altas temperaturas, a difusão intra-cristalina aumenta e leva à redução do zoneamento composicional, representando a homogeneização da composição seguida de pouca modificação durante o reequilíbrio (Tracy et al., 1976; Woodsworth, 1977; Yardley, 1977; Spear, 1993; Carlson \& Schwarze, 1997; Cooke et al., 2000).

A composição química dos anfibólios analisados mostra elevados conteúdos de $\mathrm{Al}^{\mathrm{IV}}$, de $\mathrm{Al}^{\mathrm{VI}}$, de $\mathrm{Ti}$ e de álcalis $(\mathrm{Na}+\mathrm{K})$ e indica condições metamórficas de alta temperatura e de pressão alta a intermediária (Zakrutkin \& Grigorenko, 1967; Kostyuk \& Sobolev, 1969; Robinson et al., 1982; Deer et al., 1997), sugerindo que mesmo que o anfibólio tenha se formado durante o processo de uralitização do piroxênio, está em equilíbrio com a associação mineral de fácies anfibolito superior.

As condições $P-T$ do auge metamórfico não podem ser quantificadas devido à ausência de minerais índices anteriores ao reequilíbrio (como onfacita, coesita e piropo). O reequilíbrio mais próximo do auge, ainda em fácies eclogito, é representado pelas inclusões de rutilo e quartzo em porfiroblastos de granada, que, por meio do cálculo da intersecção das isopletas de $\mathrm{Zr}$-em-rutilo e Tiem-quartzo, indicam condições de $763^{\circ} \mathrm{C}$ e 14,4 kbar.

A temperaturas determinada a partir do geotermômetro de Zr-em-rutilo, utilizando a calibração de Tomkins et al. (2007) no campo de estabilidade do quartzo- $\beta$, em cristais de rutilo inclusos em granada, para pressão de 15 kbar, é de $799^{\circ} \mathrm{C}$. A temperaturas determinada pelo geotermômetro Ti-em-quartzo, segundo a calibração de Thomas et al. (2010), em cristais de quartzo incluso em granada, para pressão de 15 kbar, é de $806^{\circ} \mathrm{C}$.

$\mathrm{O}$ reequilíbrio retrógrado em fácies eclogito/anfibolito superior é marcado pelo aparecimento de simplectitos de Naplagioclásio + Ca-clinopiroxênio, como resultado da quebra do clinopiroxênio rico em sódio devido à queda das condições de pressão. A formação de coronas de plagioclásio em cristais de granada, o intercrescimento de anfibólio nos simplectitos e o início do processo de uralitização do clinopiroxênio, além da substituição de rutilo e ilmenita por titanita, marcam a transição para fácies anfibolito superior. Os cálculos geotermobarométricos para este reequilíbrio resultam em condições de 12,5 \pm 0,8 kbar e 799 $\pm 37^{\circ} \mathrm{C}$.

As feições mineralógicas e texturais indicam que esta rocha, inicialmente, era constituída por associação mineral anidra e sem plagioclásio, estável em condições de mais alta pressão, e com a queda das condições metamórficas, principalmente de pressão, gerou texturas típicas de retroeclogito, como cristais simplectíticos de Ca-piroxênio e Naplagioclásio e coronas de plagioclásio e anfibólio em cristais de granada, associadas ao reequilíbrio metamórfico regional. Os dados texturais, mineralógicos e de geotermobarometria sugerem trajetória $P$ - $T$-t horária com descompressão isotérmica (Figura 8).

\section{CONCLUSÕES}

As condições de equilíbrio interpretadas como as mais próximas do auge metamórfico, nas amostras em estudo, indicam condições de fácies eclogito, com temperatura e pressão de $763^{\circ} \mathrm{C}$ e 14,4 kbar. As condições de $12,5 \pm 0,8$ kbar e $799 \pm 37^{\circ} \mathrm{C}$, obtidas pela associação mineral granada + clinopiroxênio + plagioclásio + anfibólio, representam o reequilíbrio retrometamórfico em transição de fácies eclogito a anfibolito superior. As condições de pressão 
calculadas para esta ocorrência de retroeclogito no Grupo Araxá, a norte da Zona de Cisalhamento Varginha, ainda que próximas, são mais elevadas que as condições calculadas por Hoppe et al. (1989) e Luvizotto (2003) para os retroeclogitos do Grupo Araxá na Nappe de Passos e na região de São Sebastião do Paraíso, que mostram condições $P-T$ de $650-700^{\circ} \mathrm{C}$ e $12,0-14,0$ kbar e de $711-799^{\circ} \mathrm{C}$ e $12,5-13,5$ kbar, respectivamente.

A reconstrução da trajetória $P-T$-t é compatível com rochas de alta pressão típicas de zonas de colisão continental, caracterizadas por espessamento crustal inicial, seguido por descompressão quase isotérmica durante a exumação tectônica.

Assim, a origem do retroeclogito está associada a colisão do Bloco ou placa Paranapanema e do Cráton do São Francisco no Neoproterozoico, indicando que as rochas atribuídas ao Grupo Araxá na região atingiram condições de fácies eclogito.

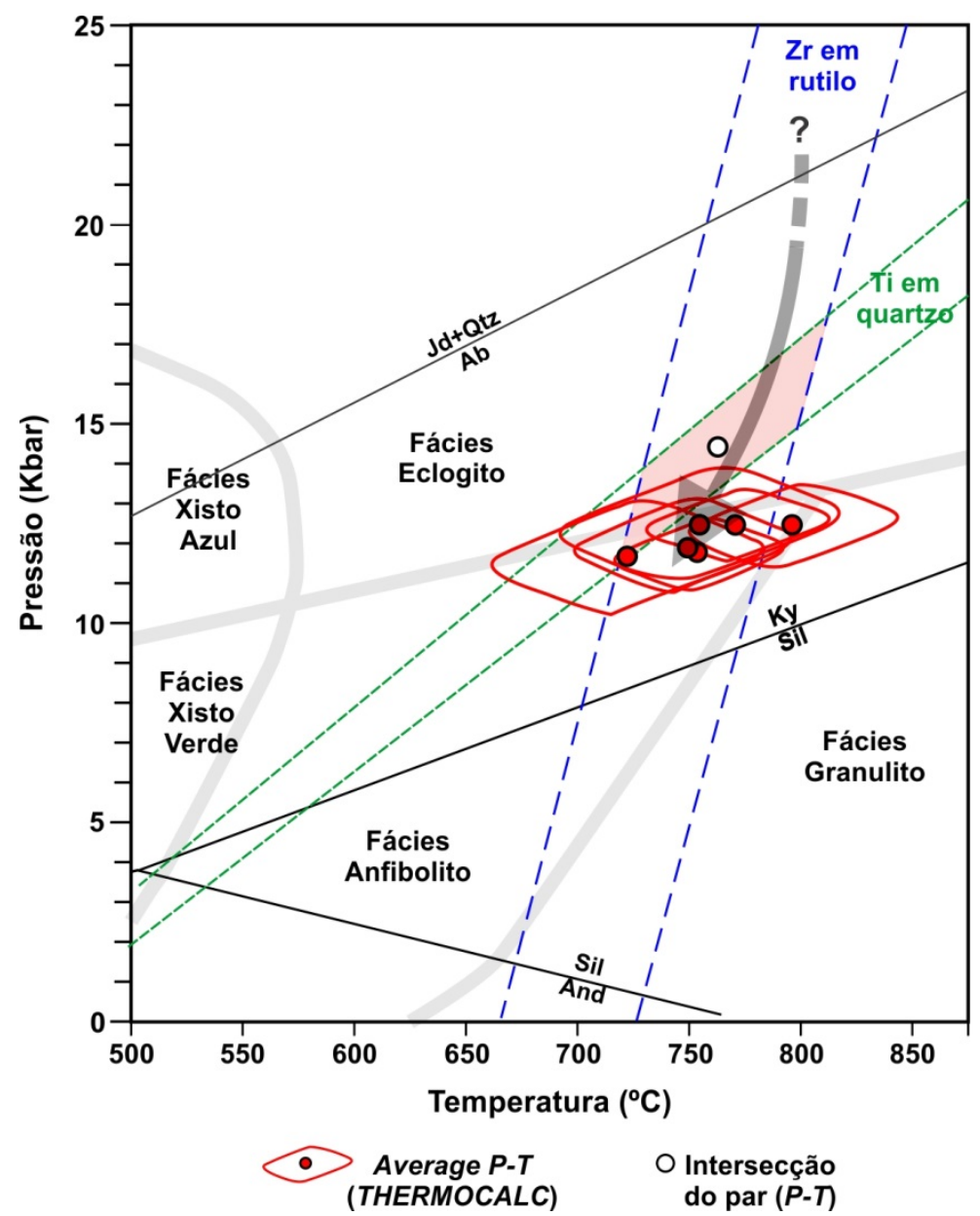

Figura 8 - Diagrama $P$-T mostrando as condições de pressão e temperatura calculadas pelo software THERMOCALC e pelo cálculo pareado Zr-em-rutilo e Ti-em-quartzo. A seta indica o caminhamento metamórfico horário. (Diagrama de fácies metamórficas modificado de Spear, 1993; linha de estabilidade da jadeíta retirada de Spear, 1993).

\section{AGRADECIMENTOS}

Os autores agradecem à Coordenação de Aperfeiçoamento de Pessoal de Nível Superior (CAPES), pela concessão da bolsa (Código de Financiamento 001).

\section{REFERÊNCIAS}

ALMEIDA, F.F.M.; HASUI, Y.; DAVINO, A.; HARALY, N.L.E. Informações geofísicas sobre o oeste mineiro e seu significado geotectônico. Anais da Academia Brasileira de Ciências, v. 52, n. 1, p. 49-60, 1980.

CAMPOS NETO, M.C. \& CABY, R. Neoproterozoic HighPressure Metamorphism and Tectonic Constraint from the Nappe System South of the São Francisco Craton, Southeast Brazil. Precambrian Research, n. 97. p. 3-26, 1999.

CAMPOS NETO, M.C.; BASEI, M.A.S.; ALVES, F.R.; VASCONCELOS, A.C.B. A Nappe de Cavalgamento Socorro
(SP-MG). In: CONGRESSO BRASILEIRO DE GEOLOGIA, 33, 1984, Rio de Janeiro. Anais... Rio de Janeiro: Sociedade Brasileira de Geologia, 1984, v. 4, p. 1809-1822.

CARLSON, W. \& SCHWARZE, E. Petrological significance of prograde homogenization of growth zoning in garnet: an example from the Llano Uplift. Journal of Metamorphic Geology, v. 15, n. 5, p. 631-644, 1997.

CAVALCANTE, J.C.; CUNHA, H.C.; CHIEREGATI, L.A.; KAEFER, L.Q.; ROCHA, J.M.; DAITX, E.C.; COUTINHO, M.G.N.; YAMAMOTO, K.; DRUMOND, J.B.V.; ROSA, 
D.B.; RAMALHO, R. Projeto Sapucaí - Estados de São Paulo e Minas Gerais (Relatório Final). DNPM/CPRM, Brasília, 1979, 299p.

CHETTY, T.R.K.; SANTOSH, M.; TSUNOGAE, T. Suture zones and geodynamic processes. Journal of Asian Earth Sciences, v. 42, p. 155-157, 2011.

COOKE, R.A.; O'BRIEN, P.J.; CARSWELL, D.A. Garnet zoning and the identification of equilibrium mineral compositions in high-pressure-temperature granulites from the Moldanubian Zone, Austria. Journal of Metamorphic Geology, v. 18, n. 5, p. 551-569, 2000.

DEER, W.A.; HOWIE, R.A.; ZUSSMAN, J. Rock-forming minerals. Double-chain silicates - v. 2A. 2 ed. London: The Geological Society Publishing House, 764p., 1997.

DEL LAMA, E.A. Petrologia das rochas metamórficas de alto grau do Complexo Campos Gerais e correlação com as do Complexo Varginha-Guaxupé: Estudos termobarométricos. Rio Claro, 1993. 132p. Dissertação (Mestrado) Instituto de Geociências e Ciências Exatas, Universidade Estadual Paulista.

DEL LAMA, E.A. Terrenos granulíticos de Guaxupé: Evolução petrológica de um segmento da crosta inferior. Rio Claro, 1998. 188p. Tese (Doutorado) - Instituto de Geociências e Ciências Exatas, Universidade Estadual Paulista.

DEL LAMA, E.A.; OLIVEIRA, M.A.F.; ZANARDO, A. Geotermobarometria em rochas do Complexo Campos Gerais ao norte da Zona de Cisalhamento Varginha. Revista Brasileira de Geociências, v. 24, n. 4, p. 1-7, 1994.

DEL LAMA, E.A.; ZANARDO, A.; OLIVEIRA, M.A.F.; MORALES, N. Exhumation of high-pressure granulites of the Guaxupé Complex, southeastern Brazil. Geological Journal, Reino Unido, v. 35, n. 3-4, p. 231-249, 2000.

HARALYI, N.L.E. \& HASUI, Y. The gravimetric information and the archean-proterozoic structural framework of eastern Brazil. Revista Brasileira de Geociências, v. 12, n. 1-2-3, 1982a, p. 160-166.

HARALYI, N.L.E. \& HASUI, Y. Compartimentação Geotectônica do Brasil Oriental com base na informação geofísica. In: CONGRESSO BRASILEIRO DE GEOLOGIA, 31, 1982, Salvador. Anais... Salvador: Sociedade Brasileira de Geologia, v. 1, 1982b, p. 374-385.

HARALYI, N.L.E.; HASUI, Y.; MIOTO, J.A.; HANZA, V.M.; RODRIGUES, C.R.V. Ensaio sobre a estruturação crustal do Estado de Minas Gerais com base na informação geofísica e geológica. Contribuições à Geologia e a Petrologia. Boletim Especial. SBG-MG, 1985, p. 71-93.

HARLEY, S.L. On the occurrence and characterization of ultrahigh-temperature (UHT) crustal metamorphism. In: TRELOAR, P.J. \& O’BRIEN, P.J. (Eds). What Controls Metamorphism and Metamorphic Reactions?. Special Publication Geological Society of London, v. 138, p. 75-101, 1998.

HASUI, Y. The Mantiquiera Province: Archean structure and Proterozoic evolution. Brazilian Journal of Geology, v. 12, n. 1/2/3, p. 167-171, 1982.

HASUI, Y.; EBERT, H.D.; COSTA, J.B.S. Estruturação da extremidade oriental da chamada cunha de Guaxupé: Dados preliminares. In: CONGRESSO BRASILEIRO DE GEOLOGIA, 36, 1990, Natal, RN. Anais... Natal: Sociedade Brasileira de Geologia, 1990, p. 2296-2308.

HOPPE, A.; KLEIN, H.; CHOUDHRURI, A.; SCHMIDT, W. Eclogitos pré-cambrianos no sudoeste de Minas Gerais. In: SIMPÓSIO DE GEOLOGIA DE MINAS GERAIS, 3, 1985, Belo Horizonte. Anais...Belo Horizonte. Sociedade Brasileira de Geologia, p. 180-192.

HOPPE, A.; CHOUDHURI, A.; KLEIN, H.; SCHMIDT, W. Precambrian Eclogites from Minas Gerais, Brazil. In: INTERNATIONAL GEOLOGICAL CONGRESS, XXVIII, 1989, Washington. Abstracts...Washington, v. 2, 1989, p. 6869.
HUANG, R. \& AUDÉTAT, A. The titanium-in-quartz (TitaniQ) thermobarometer: A critical examination and re-calibration. Geochimica et Cosmochimica Acta, v. 84, p. 75-89, 2012.

KOSTYUK, E.A. \& SOBOLEV, V.S. Paragenetic types of calciferous amphiboles of metamorphic rocks. Lithos, v. 2, p. 67-81, 1969.

KRETZ, R. Symbols for rock-forming minerals. American mineralogist, v. 68, p. 277-279, 1983.

LANARI, P.; RIEL, N.; GUILLOT, S.; VIDAL, O.; SCHWARTZ, S.; PÊCHER, A.; HATTORI, K.H. Deciphering high-pressure metamorphism in collisional context using microprobe mapping methods: Application to the Stak eclogitic massif (northwest Himalaya). Geology, v. 41, n. 2, p. 111-114, 2013.

LEAKE, B.E., WOOLLEY, A.R.; ARPS, C.E.S.; BIRCH, W.; GILBERT, M.C.; HAWTHORNE, F.C.; GRICE, J.D.; KATO, A.; KISCH, H.; KRIVOVICHEV, V.; LINTHOUT, K.; LAIRD, J.; MANDARINO, J.A.; MARESCH, W.; NICKEL, E.; ROCK, N.M.S., SCHUMACHER, J.C; SMITH, D.C.; STEPHENSON, N.C.N; UNGARETTI, E.J.W.; YOUZHI, G. Nomenclature of amphiboles: report of the subcommittee on amphiboles of the international mineralogical association, commission on new minerals and mineral names. The Canadian Mineralogist, v. 35, p. 219-246, 1997.

LEME, T.G. Geotermobarometria das rochas do Grupo Araxá e do Complexo Guaxupé na região de Guaxupé Nova Resende, MG. Rio Claro, 2019, 175p. Dissertação (Mestrado) - Instituto de Geociências e Ciências Exatas, Universidade Estadual Paulista.

LUVIZOTTO, G.L. Caracterização metamórfica das rochas do grupo Araxá na região de São Sebastião do Paraíso, Sudoeste de Minas Gerais. Rio Claro, 2003. 187p. Dissertação (Mestrado) - Instituto de Geociências e Ciências Exatas, Universidade Estadual Paulista.

MARTIN, C. $P-T$ conditions of symplectite formation in the eclogites from the Western Gneiss Region (Norway). In: FERRERO, S.; LANARI, P.; GONCALVES, P.; GROSCH, E.G. (Eds) Metamorphic Geology: Microscale to Mountain Belts. Geological Society, London, Special Publications, v. 478, 2018. First published online July 10, 2018.

MORIMOTO, N. Nomenclature of pyroxenes. Mineralogy and Petrology, v. 39, n. 1, p. 55-76, 1988.

NASCIMENTO, M.B. Evolução metamórfica PTt da porção norte do Complexo Guaxupé na região de ArceburgoSanta Cruz da Prata, MG. Rio Claro, 2010. 141p. Tese (Doutorado) - Instituto de Geociências e Ciências Exatas, Universidade Estadual Paulista.

NI, Z.; ZHAI, M.; WANG, R.; TONG, Y. Late Paleozoic retrograded eclogites from within the northern margin of the North China Craton: evidence for subduction of the PaleoAsian ocean. Gondwana Research, v. 9, n. 1-2, p. 209-224, 2006.

O'BRIEN, P.J. The petrology of retrograded eclogites of the Oberpfalz Forest, northeastern Bavaria, West Germany. Tectonophysics, v. 157, n. 1-3, p. 195-212, 1989.

O'BRIEN, P.J. \& RÖTZLER, J. High-pressure granulites: formation, recovery of peak conditions and implications for tectonics. Journal of Metamorphic Geology, v. 21, n. 1, p. 320, 2003.

OH, C.W. \& LIOU, J.G. A petrogenetic grid for eclogite and related facies under high-pressure metamorphism. Island Arc, v. 7, n. 1-2, p. 36-51, 1998.

OLIVEIRA, M.A.F. de; KAWASHITA, K.; KIHARA, Y.; DELHAL, J. Novos dados geocronológicos para rochas charnockíticas da Associação Guaxupé, Complexo Varginha. Revista Brasileira de Geociências, v.16, n.3, p.301-305, 1986.

OSTAPENKO, G.T.; TARASHCHAN, A.N.; MITSYUK, B.M. Rutile-quartz geothermobarometer. Geochemistry International, v. 45, n. 5, p. 506-508, 2007.

POWELL, R. \& HOLLAND, T.J.B. Optimal geothermometry 
and geobarometry. American Mineralogist, v. 79, p. 120133, 1994.

ROBINSON, P.; SPEAR, F.S.; SCHUMACHER, J.C.; LAIRD, J.; KLEIN, C.; EVANS, B.W.; DOOLAN, B.L. Phase relations of metamorphic amphiboles: Natural occurences and theory. In: VEBLEN, D.R.; RIBBE, P.H. (Eds), Reviews in Mineralogy. v. 9B, p. 1-227, 1982.

SPEAR, F.S. Metamorphic phase equilibria and pressuretemperature-time paths. Mineralogical Society of America, Washington, 789p., 1993.

THOMAS, J.B.; WATSON, E.B.; SPEAR, F.S.; SHEMELLA, P.T.; NAYAK, S.K.; LANZIROTTI, A. TitaniQ under pressure: the effect of pressure and temperature on the solubility of $\mathrm{Ti}$ in quartz. Contributions to Mineralogy and Petrology, v. 160, n. 5, p. 743-759, 2010.

THOMAS, J.B.; WATSON, E.B.; SPEAR, F.S.; WARK, D.A. TitaniQ recrystallized: experimental confirmation of the original Ti-in-quartz calibrations. Contributions to Mineralogy and Petrology, v. 169, n. 3, p. 27, 2015.

TOMKINS, H.S.; POWELL, R.; ELLIS, D.J. The pressure dependence of the zirconium

Journal of Metamorphic Geology, v. 25, n. 6, p. 703-713, 2007.

TRACY, R.J.; ROBINSON, P.; THOMPSON, A.B. Garnet composition and zoning in the determination of temperature and pressure of metamorphism, central Massachusetts. American Mineralogist, v. 61, p. 762-775, 1976.

TROUW, R.A.J.; RIBEIRO, A.; PACIULLO, F.V.P.; HEILBRON, M. Os Grupos São João del Rei, Carrancas e Andrelândia, interpretados como a continuação dos Grupos Araxá e Canastra. In: CONGRESSO BRASILEIRO DE GEOLOGIA, 33, 1984, Rio de Janeiro. Anais...Rio de Janeiro: Sociedade Brasileira de Geologia, p. 3227-3240.

WARK, D.A. \& WATSON, E.B. TitaniQ: a titanium-in-quartz geothermometer. Contributions to Mineralogy and Petrology, v. 152, n. 6, p. 743-754, 2006.

WATERS, D.J. $P-T$ path from Cpx - Hbl - Pl symplectites. 2003. Disp.

https://www.earth.ox.ac.uk/ davewa/research/eclogites /symplectites.html

WATSON, E.B.; WARK, D.A.; THOMAS, J.B. Crystallization thermometers for zircon and rutile. Contributions to Mineralogy and Petrology, v. 151, n. 4, p. 413, 2006.
WOODSWORTH, G.J. Homogenization of zoned garnets from pelitic schists. The Canadian Mineralogist, v. 15, n. 2, p. 230-242, 1977.

YARDLEY, B.W.D. An empirical study of diffusion in garnet. American Mineralogist, v. 62, p. 793-800, 1977.

ZACK, T.; MORAES, R.; KRONZ, A. Temperature dependence of $\mathrm{Zr}$ in rutile: empirical calibration of a rutile thermometer. Contributions to Mineralogy and Petrology, v. 148, n. 4, p. 471-488, 2004.

ZAKRUTKIN, V.V. \& GRIGORENKO, M.W. Titanium and alkalis in amphiboles in metamorphism. Doklady of the Academy of Sciences of the USSR, Earth Science Section, v. 173, p. 917-918, 1967.

ZANARDO, A. Análise petrográfica, estratigráfica e microestrutural da região de Guaxupé-Passos-Delfinópolis (MG). Rio Claro, 1992. 288p. Tese (Doutorado) - Instituto de Geociências e Ciências Exatas, Universidade Estadual Paulista (UNESP).

ZANARDO, A. Pesquisa Geológica e de matérias primas cerâmicas do centro nordeste do Estado de São Paulo e -in - kið̇i|lehadtģesnosistematização crítica da produção Técnico Científica. Rio Claro, 2003. 304p. Tese (Livre Docência) Instituto de Geociências e Ciências Exatas, Universidade Estadual Paulista.

ZANARDO, A.; DEL LAMA, E.A.; MORALES, N.; OLIVEIRA, M.A.F. Geologia da porção limítrofe entre os blocos São Paulo e Brasília. Revista Brasileira de Geociências, v.15, n. esp., p. 143-168, 1996.

ZANARDO, A.; MORALES, N.; OLIVEIRA, M.A.F.; DEL LAMA, E.A. Tectono-Lithologic associations of the Alterosa Paleo Suture Zone - Southeastern Brazil. Revista UnG Geociências, v. 5, n. 1, p. 103-117, 2006.

ZHANG, J.; ZHAO, G.; SUN, M.; WILDE, S.A.; LI, S.; LIU, S. High-pressure mafic granulites in the Trans-North China Orogen: tectonic significance and age. Gondwana Research, v. 9, n. 3, p. 349-362, 2006.

Submetido em 10 de março de 2017 Aceito em 4 de setembro 2018 